\title{
The Event Ontology of Nature
}

\author{
Said Mikki
}

check for updates

Citation: Mikki, S. The Event Ontology of Nature. Philosophies 2021, 6, 88. https://doi.org/10.3390/ philosophies6040088

Academic Editor: Marcin J. Schroeder

Received: 30 July 2021

Accepted: 23 September 2021

Published: 19 October 2021

Publisher's Note: MDPI stays neutral with regard to jurisdictional claims in published maps and institutional affiliations.

Copyright: (C) 2021 by the author. Licensee MDPI, Basel, Switzerland. This article is an open access article distributed under the terms and conditions of the Creative Commons Attribution (CC BY) license (https:/ / creativecommons.org/licenses/by/ $4.0 /)$.
International Campus, Zhejiang University/University of Illinois at Urbana-Champaign (ZJU-UIUC) Institute, Haining 314400, China; said.m.mikki@gmail.com

\begin{abstract}
We propose a new event ontology of the world, which is part of a general approach to philosophy based on combining ideas from science, ontology, and the philosophy of nature. While the position advocated here is grounded in science and philosophy, it attempts to move beyond each of them by devising and exploring a series of technical (naturalized or naturalistic) ontological concepts such as Interconnectedness, the Whole, the Global, Chaos, the event assemblage, and Nonspace. A central theme in our event ontology is the mapping out of a fundamental critique of the theory of the organism and organization, especially when the latter two are viewed as processes in spacetime. In particular, and following earlier leads, we criticize the spacetime doctrine by arguing that it is not ontologically fundamental, where we suggest its replacement by more primordial naturalized ontological concepts of space such as ontospace and Nonspace. The event ontology of nature can be considered a radical alternative attitude toward the relation between the human and nature, an attitude, in fact, that has been repeatedly explored, though under very different headings, by numerous scattered thinkers throughout the history of ideas. We examine some of the past thinkers who contributed to this general but still incoherent body of thought, including Leibniz, Heidegger, Simondon, Ruyer, Deleuze, Whitehead, and Guattari. The goal of this article is to provide a condensed high-level view on this very complex and still evolving subject intended for a large audience, not necessarily only philosophers, but also scientists, mathematicians, technologists, theologians, sociologists, artists, and psychologists.
\end{abstract}

Keywords: philosophy of nature; ontology; events; spacetime; space and time; organism; Martin Heidegger; Gilbert Simondon; Deleuze and Guattari; Bertrand Russell; Alfred North Whitehead

\section{Introduction: Overcoming Ontotheology as a Transitioning into the Event Ontology of Nature}

Throughout its history, the philosophy of nature has entertained a curious relation with mythology, religion, and theology, especially before the emergence of modern science, mathematical physics, and ontology [1]. This is especially true in the philosophy of A. N. Whitehead, whose classic book Process and Reality ended up with a surprisingly strong ontotheological-or even cosmogenic-coda [2]. In fact, such a relation between what-at least presently - is often treated as a "fairly scientific" discipline, the philosophy of nature, with other, allegedly "less scientific" areas, such as theology, ontotheology, mythology, cosmogony, theogony, etc., should not be surprising. The philosophy of nature has always been a bold and independent direction of thought critical of not only theology but also science itself. However, in several philosophical circles nowadays and the recent past, there seems to be a desire to move back to ontology through ontotheology [3-6]. ${ }^{1}$ This is also happening within a general long-term revival of interest in the philosophy of nature both within the Continental [7-10] and Analytic Traditions [2,11-14]. In both cases, it appears that a return to ontology must be conducted through the infamous Heideggerian "destructive reconstruction" of the history of metaphysics [15-21], especially his very formulation of the concept of ontotheology as a negative or limitative construction of ontology as such [22-27]. ${ }^{2}$ Heidegger's early attitude toward theology is most often discussed in terms of his relation with figures such as Paul, Luther, and Eckhart $[24,25,33]$, and the manner by which the standard 
Heideggerian ontological categories of releasement, unconcealment, comportment, had been influenced by such religious roots. However, an alternative path is also possible by which Heideggerianism, at least in its main thematic outline, is deployed in order to re-develop a philosophy of nature that bypasses Idealism and traditional theology by taking into account Heidegger's critique of the history of philosophy, in addition to his ontological concepts developed in other texts. Such an approach was adopted by certain thinkers, for example, Zubiri [34-38], and Jonas [39,40], who also happened to be former students of Heidegger.

In contrast to the standard approach, we wish to suggest the possibility of establishing a new orientation of philosophy which takes its point of departure from a radically different reinterpretation of the "ontotheology of nature" but this time while seeking a positive view of the world and the cosmos diverging with-or even overcoming-the limitative mode often associated with past ontotheological positions found in the literature. Indeed, ever since Heidegger's early work [24], ontotheology has been negatively defined as the ultimate critique of the very possibility of ontology as such. ${ }^{3}$ Nevertheless, we also believe that a positive engagement with postmetaphysical modes of ontology is still possible. One way to achieve that, we suggest, is by working through concrete dynamic ontologies of the Real, the mode of being-there closest to Nature, instead of the traditional focus on Dasein as related to the human being [31], yet while still taking into account Heidegger's conclusive destruction of the history of Western metaphysics. Such simultaneous processes of overcoming and moving beyond ontotheology, executed through a full commitment to the philosophy of nature, is what we propose to treat in this article under the rubric of the event ontology of nature.

The event-based approach to the philosophy of nature is critical of both science and theology, yet while managing to steer clear from the traps of both atheism and irrational belief [46]. Moreover, the event ontology of nature moves beyond conventional ontotheology as such by presenting itself as a positive contribution to the field of the ontology of nature (understood as a subfield of the philosophy of nature). The naturalistic position of event ontology is rational but without necessarily being axiomatic. Here, Nature becomes the Absolute, Chaos, the One, the Whole, the Global, the Fountainspring of Being, and so on, yet while evading binding commitments to any specific ideology. ${ }^{4}$ The program is not new, for we may argue (though we will not do so below) that some ancient philosophies, for instance the Ionian physiologists, Taoism, and Stoicism, represent a form of thinking the Absolute, the Unlimited, the Whole, by which the Absolute becomes continuous with Nature and Nature gets its meaning from the ontology of such Absolute. However, it is also not the Absolute of German Idealism [53-55], nor that of a personal deity [56], but a concept closer to what the founders of ancient thought and the major religions intuitively sensed and felt through a direct communion with Nature itself. Whitehead's great book The Concept of Nature [57], with its event ontology of the world, and the ontotheological framework he developed in his magnum opus Process and Reality [2], are remarkable modern examples illustrating how such a thousands-of-years-old approach to nature through ontotheology could be revived in the century of science and mathematics.

To reject theology one does not need to become an atheist. To refuse to be an atheist there is no compulsory reason to advocate theology. We believe Nature can be approached through a special attitude that we may loosely describe as "rational faith or belief": an anti-theological - yet not irrational-attitude toward the direct communal of the human with Nature (Gnosis, or fundamental knowing [40,58]). This is a philosophical worldview informed by science and mathematics, though not afraid to speculate about the Absolute or Univocal Being while remaining, in the main, roughly compatible with the ethical-but not theological-imperatives of religion. Examples of past thinkers who worked with science, logic, and philosophy, on one side, and theology, on the other, include Aristotle [59], Cicero [60], Seneca [61,62], Plotinus [63], Proclus [64,65], Avicenna [66,67], Averroes [68,69], Bruno [70], Duns Scotus [71], Leibniz [72], Schelling [73], Whitehead [2], Heidegger [30], and Zubiri [34]. In our view, each one of these thinkers, and others not mentioned above, 
had contributed in his own manner to the problem of the event ontology of nature, though obviously without always using the technical term 'event' itself. Explicating in details how does that happen with each relevant past thinker is an interesting topic of philosophical research into the history of ideas, but is outside the scope of this article. For us, the key feature in the thinking of, say, the stoics, is the integration of nature with both science and the humanities (ethics), a unity of science and the social field of experience that is most clearly seen, for instance, in works such as Spinoza's Ethics [58]. From our perspective, speculative natural philosophy includes the event ontology of nature, an opinion that may justify the excessive focus to be found below on both science and philosophy, but also while hinting at their inherent limitations. ${ }^{5}$ Transcending science and philosophy leads us directly into the realm of the event ontology of nature. The latter position, once established, might be deployed in order to ground an ethical approach to life. (However, the ethical theory will be addressed elsewhere).

A characteristic feature of ontotheology, as can be easily noted from the term itself, is the primary importance of ontology, traditionally a branch of-or maybe better say, an approach to-metaphysics that emphasizes formal and precise thinking about being, becoming, and existence. Historically speaking, ontotheology has been seen as a negative critique of western metaphysics emphasizing the latter's involvement with reducing being into presence, a position severely and consistently criticized by Heidegger. This is, however, a "negative ontology", that is, basically it is a project of a legislative critique as in Kantian philosophy in general. ${ }^{6}$ In order to develop a more positive approach which yet remains post-Heideggerian (in the sense of being mindful of the collapse of the ontologies of presence), we emphasize an alternative ontological perspective. Indeed, for the specific program of the ontology of nature that the following series of reflections revolve about, we highlight event ontology as a major theme in our presentation. The event can be provisionally defined as a fundamental, nonperceptual happening that form the basic building block of the Real as such. Everything in the world, including people and things, can be constructed from events. There is a long history behind this approach, which cannot be revisited here in detail. It is enough to mention, for example, Leibniz's Monadology [72] as a particularly famous example of event ontologies. However, probably the first complete event ontology of nature is due to one of Schelling's various formulations of his ever changing philosophical systems of nature, the text where he introduced the concept of Aktions, roughly synonymous with events as we understand them here [85]. In recent times, the subject appears to have attracted the attention of several philosophers, for example Russell [86], Whitehead [57], Deleuze [87], and Heidegger [30], but again while each thinker is found to be engaged in developing, expanding, and advancing the subject in his own distinctive and unique mode of inquiry.

Through our event ontology-focused perspective, the particular version of the philosophy of nature to be dealt with here should always be understood as an ontology of nature transcending the naturalistic per se. That is, this is not an ontology of God. Nor it is another philosophy of transcendence, such as Idealism or traditional religions based on concepts of personal deity. Instead, we suggest that the event ontology of nature may be viewed as an attempt to go beyond nature into Nature, where the latter capitalized term is akin to Heidegger's distinction between beying and beings [88-90], through which he upgraded his earlier theory of the ontological difference based on being/beings [31]. Nature may be interpreted in different ways, whether as God, the Godhead, the Whole, the Global, the One, and so on. The event ontology of nature, then, is both a post-scientistic and a post-theological approach to Nature that nevertheless draws heavily on ideas directly taken from or inspired by philosophy, science, and ontotheology.

The event ontology of nature is defined by its opposition to linking Nature to piety. In other words, event ontology does not attempt to construct theological concepts of deity, whether residing in nature (monotheism, polytheism), or even continuous with nature as such (pantheism). Instead, this program starts with science then proceeds beyond science itself through an internal critique of scientific concepts. Some of the concepts proposed by 
event ontology in order to bypass the strictly naturalistic attitude include Chaos, the Whole, the Global, Interconnectedness, and Nonspace. It is highly likely that in time, and as the natural sciences and mathematics advance enough, our understanding of some or all of these concepts, which we dubbed event-ontological, may allow us to "downgrade" them into the status of the ontological, and even possibly the scientific (just think of concepts such as entropy and black holes in modern physics, which would have had been considered metaphysical, or even theological, constructs a mere three centuries ago).

This article is organized as follows. In Section 2, we briefly sketch out a selected group of what we believe represent the main features of the program of the event ontology of nature, especially as seen through the prism of past thinkers whom we interpret as belonging to such general orientation of philosophical thought. In Section 3, we narrow down our focus to examine more carefully two main thinkers, Raymond Ruyer and Gilbert Simondon, who started to attract attention in recent years as major philosophers of nature from the twentieth century who happened not to receive the full attention they deserved in their own century. We intentionally chose Ruyer and Simondon because of our admiration of how they constructed their detailed examinations of biological aspects of nature within a rigorous formal and novel ontological perspective. Since the problems of spacetime and the organism are key dimensions of the program of the event ontology of nature discussed in this article, their respective philosophies serve as excellent preparatory departure points for the transition to the next few sections. Indeed, in Section 4, we look into the nature and function of spacetime in both modernism and postmodernism and introduce the viewpoint of the event ontology of nature. This is followed in Section 5 by a brief treatment of the problem of the organism, first within spacetime, followed then by suggesting the need to move beyond the traditional spatiotemporal framework by explicitly utilizing naturalized ontological categories such as Chaos, the Event, Nonspace, and the Whole. After establishing a positive approach to the problem of the organism in nature, inspired by event ontology, Section 6 provides a critique of modernism and spacetime in general, tying up the various threads of the previous Sections' treatments of the problem of the organism and organization within the framework of that specific brand of mathematical physics characteristic of the modernist attitude, yet while arguing meanwhile for the need to move beyond such a rigid philosophical outlook. By way of an "application" of the theoretical main text, we provide in Section 7 a reexamination of the problem of pantheism in light of the program of the event ontology of nature, where we elaborate our opinion that despite some overlap in their respective positions, the two philosophical positions remain fundamentally distinct, at least on the formal ontological level. Finally, we end up with a series of conclusions. Two Appendices A and B are provided at the end of this article. Their function is to summarize some of the main technical aspects of event ontology by going into more details than what can be found in the main text.

\section{Nature, Life, and Interconnectedness}

The idea of Life goes beyond biology. Life is a perspectival aspect of Nature's philosophical field of vision [91]. In the past, it was claimed by nature philosophy (German romantic thinking?) that Nature is Life, nothing less, nothing more [54]. (Think, for example, of Marcuse's interpretation of Hegel [92], and the various ways in which people tended to rethink German Idealism and Romanticism). However, Life does not exhaust Nature as a whole because the living being is only a formative local force acting, working, and shaping what happens inside its boundary through the being's ownmost contexual horizons of occurrences, metamorpheses, and expectations. This is all while Nature continues to encompass the sum total of everything that transcends this inherently localized sphere of happening and action. Nature is the Global. The Global is not something to be merely opposed to the Local, though at various occasions we will have to do something like this. However, even while unintentionally binarizing the comparison between the two fundamental ontological concepts, it is important to keep in mind that the Global is much more than the sum total of connected "parts", each considered a "locality" on its 
own. A sum of locals does not give rise to a Global Whole [93,94]. It is more accurate to state that the Global emerges out of the web of interconnected local fields working with their contextual horizons of creations. Global Force is an emergent order of the Real that comes into being through a historical process of development paralleling-and in fact grounding-ontogenesis [7].

One may view Life as a cosmic ecosystem constituted by some sort of "total web of interconnected things", a grand vision akin to Leibniz's [72], Schelling's [85,95], and Humboldt's [96] holistic thinking. However, what kind of "connection" did those thinkers have in mind? True, the animal and vegetable worlds are deeply interwoven into each other, and what happens at one spot within a united ecological system may affect, directly or indirectly, everything taking place at other locations. So ecosystems are inherently nonlocal, but that in itself does not explicate the ontological foundations of that grand universal connectionism so admired by holistic thinking $[97,98]$. We probably need to search for additional gateways, wider key passages, and deeper insights into the technical content of what it means to say that one element in nature is connected with others. Is connectionism to be understood here physically, chemically, physico-chemically, biologically, metaphysically, psychologically, or theologically? One does not get to know the answer while reading Leibniz [72,99,100], Humboldt [96,97,101,102], Mach [103,104] and Whitehead [2,57,77,105]. Maybe what they all had in mind is $a$ form of interconnectedness, rather than connectedness as such. If that is case, then the philosophy of nature needs to press forward toward a more careful substantial filling up of the gaps and void left by earlier formulations. ${ }^{8}$

The fundamental pattern of interconnection between various zones of Nature should not be conflated with the ontologically rudimentary order that is effective at the relatively more primordial level of events and event assemblages. Wings, eyes, and bellies are actualized organic strata of being that are themselves "final products" effectuated by underlying event assemblages. However, you may view one level of interconnectedness through which, for instance, a self-subsisting wing couples with an abdomen, in accordance to their own reciprocal modes of inter-relatedness-to-the-other, for the "purpose" of forming a new beast. The "total animal", say a monster, is the outcome of processes of ubiquitous connective synthesis, not sparing even "inorganic stuff" like stones and air, all marching along the trajectory (not always an advance) of perpetual evolution/devolution of complex life forms. However, such couplings between organs, quasi-organs, non-organs, and so on, in order to form "anything-that-can-go", is still a phenomenon happening after the formation of natural objects. Organic and inorganic beings are formed entities. Events are still more fundamental than being merely negations of observable and macroscopic or molar zones of being. The event is even more primordial than elementary particles like electrons and quarks: only the event is of the Real and in the Real, while organs, nonorgans, and other regimes of objects, are already actualized beings, and hence ultimately objectifiable entities, "late products" when measured against the natural scale of onto-dynamics going from events to event assemblages, higher-order event assemblages, and so on.

Elementary particles are produced by events. Inorganic matter is produced by events. Organic matter is produced by events. Inorganic fields are produced by events. But events form among themselves the originary nexus of interacting actors (event assemblages) that define, inform, and constitute all those later objectified entities, molecular or molar beings. Clearly, conventional mainstream science, with its ever more exacting focus on disciplinary models conducted by the specialist and expert, is not really concerned with the construction of such very grand cosmic picture of all beings and their embeddedness into Being. The event-based ontology of nature, on the other hand, is freed from the specialist approach because of the former's inclination to infuse an "upgraded" or sublimated quasi-theological dimension of immanent experience into the ontology of nature but without falling back onto the transcendental concepts of Deity, Divinity, Trinity, or the Absolute Subject. Event ontology provides one possible mode of viewing nature which, before the advent of the materialist postmodern ontologies, was dealt with previously mainly through religion, i.e., the conception of "the grand chain of all creatures", with the 
exception that now the term 'creature' should be replaced by 'beings', where the latter is understood as event assemblages (say in the spirit of Deleuze and Guattari [9]). So what does the classical concept of the grand chain of beings mean? It is a post-evental occurrence of a secondary form of holism, the holistic Leibnizian-Schellingian-Humboldtian cosmic interconnectedness of all lifeforms [72,85,95-97,99-102]. Concepts of the Great Mother Earth [112], Gia [113,114], Cosmos [101,102]. This is the classical Preplatonic-StoicNeoplatonic-Leibnizian-Schellingian-Humboldtian-Whiteheadian Concept of Nature. On the other hand, among events themselves, amid their vast orchestrated interactions through conditions of consistency (harmony), regularizing nonspatiotemporal "contact" between their "intercoursing" onto-flows, something totally different takes place: It is the erupting coming-to-be of a more originary ur-ground serving as an abyssal ground for the beingin-connected-ness of that connectivity which grounds higher-level interactions (between molar and molecular already objectified beings), and the primary event-flow as such at the lower level (even while the latter can never be reduced to the former's "substance" of the evental web of the Whole's event-assembled-ness).

\section{Ruyer and Simondon}

In the post-war period, or better say the post-Heideggerian era of twentieth-century thought, the center of gravity of philosophical production shifted from the Germanspeaking sphere to the French-speaking world, especially Paris. A series of important thinkers emerged into the scene, starting with Sartre, Merleau-Ponty, and going through Althusser, Foucault, Simondon, Ruyer, Guattari, Baudrillard, and Serres. Here, we will single out two fundamental figures whose main work has not been fully appreciated (at least not within the English-speaking world) until recently: Gilbert Simondon [7,8,115-120] and Raymond Ruyer $[10,121]$. Generally speaking, one may initially argue that these two thinkers have their roots in the philosophies of Leibniz [72] and Schelling [85]. Indeed, though the methods are different, the underlying spirit animating their respective adventures are the same. Both had been inspired by a deep engagement with biological thought and the living world, somehow breaking with an old tradition where philosophers often tend to focus on physics when it comes to "interrogating" nature (Aristotle and Bergson are clear exceptions to this). No detailed examination of their respective ontologies will be attempted here. Instead, we just highlight some selected features of their thought relevant to the event ontology of nature program, our main concern in this article. In our opinion, this particular body of work by Ruyer and Simondon, which has become influential in recent times-largely due to its impact on major French theorists such as Baudrillard, Deleuze, and Guattari-deserves more critical attention in the secondary literature. In what follows, we concentrate on the minimal technical ontological features of their respective programs needed in order to prepare for the transition to the fundamental critique of the spacetime doctrine that will occupy us in later sections.

Simondon's ontology of individuation [7,8], and Ruyer's architectonic of primary forms [10], both fit nicely and smoothly into the Leibnizian ontological schemas of development, devolvement, ${ }^{9}$ and monadology [72]. Simondon [7,8] is bringing to us the full vitality of ontogenesis, now constituting the true theater of ontology: the production of the Real. On the other hand, Ruyer, who anticipated and grounded Simondon's own thinking, reinvigorated the Leibniz-Schelling doctrine of monads/acktions [72,85] that finds other advocates in the systems of Mach [103], Russel [84,86,125], and Whitehead [2,57]. Primary forms in Ruyer [10] are quasi-events, that is, not true events in the full technical sense of the current understanding, the reason being that Ruyer-like most French philosophers from Bergson [126-128] to Deleuze [87,129] — thinks largely within mainstream science, not outside it; that is, concretized ontic categories encompassing spatiotemporal bodies and material objects (the Heideggerian present-at-hand mode of being $[17,31]$ ) have tended to dominate the mature systems of French thought and its philosophy of nature. ${ }^{10}$ Nevertheless, the advance made by the philosophical generation around Bergson [128] up to Guattari $[130,131]$ is enormous, and that is especially true when it comes to the last link 
in the chain, Guattari, who, to the best of our knowledge, appears to be the only one in French Theory not to buy into existing "scientific practice", and hence he stands aloof from ulterior considerations such as the desire to be published, heard, taken seriously by the establishment, and so on [132,133].

Now, going back to Simondon $[7,8]$, what we find most relevant to our project in this extraordinary philosophical itinerary is the manner by which he creatively appropriated ideas in Ruyer's and Bergson's thought ${ }^{11}$ by placing them into a more universal or allencompassing context, that of the morphogenetic framework of Nature's createdness [7] that had fully guided and determined the parameters of the Ruyerian system of nature [10]. Simondon's ontogenesis and philosophy of individuation are bold and original, even while we may balk at his fully-fledged embrace of individuation. For it is not clear whether Simondon would withstand the fundamental Heideggerian critique of Western metaphysics [89] if, in a hypothetical scenario, the former came under the fire of the latter's philosophical wrath. It is not a mere "thought experiment" what we are trying to present here. The issue is much more subtle than just a comparison between Heidegger and Simondon (or Ruyer). There is something missing in most French ontologies (probably with the mild exception of Guattari), and that is a clear break with Nietzsche's philosophy of Life [136-138] and its closely related association with becoming [139,140]. Being and becoming should not be inserted into new dualistic thinking, but instead need to be approached with extreme caution. Incomplete philosophical formulations or hastily grafted axioms tend either to conflate being and becoming [55], or mistakenly mark them as polar opposites [141-143]. The event ontology of nature intends to avoid falling into such philosophical traps that have ensnared and hindered several previous attempts (including even Whitehead's system, which we consider only partially successful in this regard).

Yet, we cannot approach the idea of the individual without first considering the process leading to the production of that individual: individuation. In essence, this is precisely Simondon's position [7,8], which, in our opinion, is fundamentally correct, and, at least with regard to its thematic outline, is in conformity with Leibniz [72] and Schelling [85]. However, one may wonder whether it is possible to even mention the term 'individual' here without falling into some form of an ontology of presence. The situation is not considerably different from what was discussed in earlier systems regarding the so-called "problem of the body", where we find that the Stoics, Spinoza, Nietzsche, and Deleuze, had all taken an affirmative stance toward lifeforms centered on or immanent in bodily nature, leading to the remarkable endurance of the ancient concept of the incorporeal and its surprise coming back into our present time [144]. However, neither the body nor the individual can be taken for granted, since, still, their foundations lie in the perceptual and cognitive apparatus of a knowing Subject, and hence we need to steer away from all types of "the philosophies of the body" lest we get entangled with the reactionary claim of an inevitable return to Idealism in such case. ${ }^{12}$ Nor it is enough to declare allegiance to some philosophies of genesis, creation, production, and so on, in which the ontological priority of the body or individual is relegated to the background, while the process leading to the becoming-here/there of individuals is elevated to the topmost floor of metaphysics' conceptual pyramid. In other words, replacing the individual by individuation is a great leap forward, but by itself is not that revolutionary. Deleuze's shortcomings [87] arise from precisely this observation: he could not elaborate a detailed formal ontology capable of explicating bodies and individuals without presupposing that toward which creation is comporting itself: being = present. If we have to completely purge presence from philosophy [31], then one cannot even speak of individuation (not to mention the more abstract concept of the the preindividual [7]) without committing to some implicit utilization of perception and cognition, and hence postulating presence as the ultimate (though not explicit) starting point of ontology $[15,17]$.

\section{Spacetime and Ontology}

Now let us inquire more carefully into that elusive "something" lurking slyly in each of the two-competing-systems of the philosophy of nature and theology, a malicious, 
utterly "invisible hand", persistently re-injecting into our various postmodern formulations precisely those abhorrent ontologies of presence, the demolition of which had been the central preoccupation of the early Heidegger's project of fundamental ontology and ontotheology. Our basic position, originally inspired by Being and Time [31] on one hand, and Heidegger's critique of Kant on the other $[15,17,145,146]$, is founded on identifying the key culprit as a fundamental cornerstone of both modern metaphysics and mathematical physics: the doctrine of spacetime. The event philosophy of nature, executed, for example, by way of an ontotopological theory of the event as a flow, ${ }^{13}$ aims at replacing a primary spacetime by a more primordial level of reality comprised of events [86] ${ }^{14}$ In what follows, we provide some very general remarks on this theme, whose importance for our immediate purposes here is reminding us of the need to avoid carrying out the project of the event ontology of nature within a philosophically negative orientation. That is, while the ontologically fundamental status of spacetime is rejected in our perspective, it should be kept in mind that such a negative position is embraced by event ontology only in order to unconceal and make available a hitherto hidden pathway leading up toward a more positive fundamental understanding of life and the cosmos that affirms Nature: the state of intuitive apprehension of natural being centered on concepts of the event, Chaos, the Open, Nonspace; in a nutshell, everything pertaining to event assemblages and their nexus of inter-evental couplings and interactions $[2,57,84,105]$. Note that the constructive component of the project of event ontology as a domain in the ontotopology of flows and their interactions is itself a highly complex technical subject, see Appendix A for a very brief and dense overview of our system.

Spacetime is fundamental for the modern mind's conception of the world. As we will see later, it is also essential for the operation of the conventional theological mode of thinking, where issues such as "the location of the Godhead", the "position of the divine", the "topos of the almighty One", have been debated for centuries and millennia. ${ }^{15}$ The fundamental key text of the modern theories of spacetime is Weyl's 1917 lectures Space, Time, Matter [147], which in many different ways may be considered the founding textbook of modern mathematical physics. There, the orthodox ontological concept of the event, still essentially unchanged in current mainstream physics and philosophy of science, was construed as that of the spacetime point. It is crucial to note that for Weyl, as also in Descartes $[141,142,148]$ and Einstein $[149,150]$, spacetime provides the rigorous realization of matter as extension. The "dynamization" of space by "injecting" time as a fourth dimension is, according to Weyl, the last piece needed to complete the CartesianGalilean project of mathematizing nature [151,152].

On the other hand, everything in the ontology of nature is a revolt against the spatiotemporal dogmatism of modern mathematical physics, best captured by Weyl's philosophy, with its twin emphasis on geometry and number [151]. The event ontological concepts of the Global, Nonlocal, Interconnectedness, Chaos, and others, whose "inexact essence" overflows the narrow disciplinary confines of mainstream science [32], emphasize a purely topological relational structure underlying the Real as such $[153,154]$, and hence are intrinsically non-metric, or even better say anti-metric in and through [9]. This non-metric character was already emphasized by Russell in his early work on fundamental ontology, often published as research into the foundations of mathematics [155-159], before it was rediscovered and revived by Simondon [7] and Deleuze [87,129]. It is also an essential feature in Heidegger's project [154] and also Whitehead's [2].

However, such intense preoccupation with the topological should not be taken as an attempt by the event ontology of nature to reinstate a new theological concept of space similar to Plato's receptacle [160] or Newton's Absolute Space [161]. Neither should some vague Big Space be posited as an absolute ontological category controlling the sum total of the various microprocesses of being-there taking place in nature. Instead, the ontological structure spatial-as-positionality-in-itself must to be rejected and replaced by alternative, more fundamental meta-ontological schemas, such as Nonspace, which is a negative quasi-theological concept similar in rank and importance to Leibniz's Fold [99], Deleuze 
and Guattari's Chaos [51], and Russell's Superset (the set of all sets as the Inconsistent Whole [155-157,162,163], but differing from them in being technically designed to be geared toward working with event assemblages, where the latter are to be understood ontotopologically.

Moreover, Nature is neither reducible to the merely organic, nor is its essence exhausted by the concept of the holistic. A viable ontology of the future is that which destroys and constructs alternatives at the same time, a continuous process of creative destruction in which the overall naive materialistic framework of tradition gets replaced by the post-spatial, post-temporal, that nonspace of eternity without time, the Absolute that is dissolved into flows and the fluidity of becoming-other. We need to learn how to slowly digest Nature, absorbing into the mind thoughts nonhuman and irregular. The post-spatial takes us beyond even the trans-spatial. The post-temporal is non-temporal and anti-eternal. Maybe we need to appreciate the noological puzzle of how thought may exist outside the thinking body of the subjective present. No futurity included, no coming-to-be of that which never was. There is only one path: to break free from the rigid structure of causally-connected, saptiotemporally-defined events. In this sense, quantum theory [164,165] does have something valuable to teach us, probably more important than what Einstein [149] or Weyl [151] had brought to modernism [166]. Conventionally speaking, the precise inceptual moment of the modern (in science) is that inaugurated by the so-called "relativistic revolution" [167], and hence the need to carve out something new and different. However, the quantum is not a simple replacement of the relativistic. The basic lesson of microscopic physics is that spacetime loses its status as the theater of the Real, surrendering this royal position to the next in kin, the wave function of Schrodinger and the operator calculus of Heisenberg [168]. There must be something more here. The physics of spacetime giving way to the perpetual dynamism of the infinitely small $[169,170]$. Well, does that mean that there exists enough information encoded into smaller subregions of spacetime? No, for the very idea of the Quantum Revolution is that nothing given is known in advance, but is instantly created by the very process of being given [171-173]. Think of nonhuman observers acting in a quantum world where everything is "prepared" by some nonsubjective processes of onto-organization bypassing rules, laws, and nomos. Is this the birth of new physics, or the end of metaphysics? Maybe both. We are ready for a speedy return to natural philosophy.

However, before moving forward, a word of caution regarding our terminology. Since we have been operating largely from within a Heideggerian and postmodernist perspective, a critique of all idealistic conceptions and constructions is to be taken for granted in the event ontology of nature. So, the reader may wonder, What is this "Absolute" mentioned above in conjunction with naturalistic event ontological concepts, Nonspace for instance? This is not a return to Hegelian metaphysics [54,55] nor some other ontologies of the absolute that may be found in certain texts by Schelling $[53,174,175]$. The issue is that the complex formula we call "the event ontology of nature" must include elements taken from (1) ontology, (2) theology, and (3) the philosophy of nature, where the last field contains science as a subfield. However, in its unique synthesis of all these elements, this particular vision of the ontology of nature would, quite naturally, transcends or sublimate all of the elements listed above by producing a higher vision of the totality of all things out there. Originally borrowed from theology, the Absolute is a compromise, which we are forced to re-appropriate and re-adapt only for lack of better terms, not concepts; but the exact sense allotted to the technical concept of the Absolute per se found therein is quite different from the well-known significations famously (or infamously, depending on who you are) associated with German Idealism, Christian theology, and Sufism. Against those latter garden-variety theological, religious, and mystical attitudes, we advocate a concept of Nonspace as a non-totalized totality that evades all of the formal apparatuses of spatial operations such as inclusion, part-whole, being-in, being-near, etc. In this sense, the Absolute is never a totalizing category, nor a transcendental operation, nor an external God, nor an unlimited Subject, nor an Infinite Being. The Absolute is simply that relational aspect of Chaos to be materialized when the latter is viewed from the perspective of the 
production of event assemblages as in Deleuze and Guattari's profound concept of the plane immanence (latter defined as the section of Chaos that produces a solution to a problematized configuration or a problematic field of infinite creativity [51]).

\section{Organisms and Spacetime}

In mathematical physics, spacetime consists of a collection of points with some extra structure added on top of them $[147,176]$. The 'point' in itself enjoys no ontological significance $[57,125]$, since it is only the nexus of relations connecting various points what really matters $[7,86]$. However, how could an organism know this? If we say that all organic processes are ultimately capable of becoming embedded into the spacetime of physics inside which all physico-chemical events take place, then does this imply that being an organism is in essence reducible to such bare-bones situatedness of clusters of point-parts or "organic elements" with respect to each other in spacetime? Can I deduce everything the organism can do from "readings" registered in spacetime, say measurements of various physico-chemical fields as we find in the traditional disciplinary scientific domains of physical chemistry, biophysics, biochemistry?

It appears that this is how modern biologists in general, and Darwinian philosophers in particular, actually think $[177,178]$. For them, the organism is effectively the complex outcome of a vast web of inner interconnections coupled with what is essentially a random and completely separate outside world: the environment. In mainstream biology, there is a fundamental distinction between the organism and its surrounding field inside which the former thrives and develops. Even though both organism and its environment are composed of the same material stuff, say same chemical elements or fundamental particles, the order of difference between the two-as approved by Darwin himself-is enormous. The organism is a complete individual with specific programmable directives and one "goal": survival, while the environment is generally hostile, unpredictable, and overtly mechanistic, much more so than the organism itself [179]. Therefore, mainstream biology would still confer on the organism that which it withheld from the environment: goaldirectedness, even while remaining within the narrow and extremely thin framework of Darwinian natural selection or the survival of the fittest doctrine. Note that this conclusion remains true even with the more recent revisions of evolutionary theory influenced by paleontology and the development of the earth sciences, where a tighter connection between environment and the organism, going beyond what early Darwinism had originally anticipated, has been roughly acknowledged [180]. In any case, even after endowing the earth system with a superior intrinsic dynamism, vitality, and adaptability, sometimes even making the Earth resembles a self-subsisting "giant organism" standing on its own [114], mainstream biological thinking continues to attribute to the organism a separate existence but in the specific physico-mathematical technical sense of being seen as essentially a process in spacetime, whether as a coherent macroscopic zoological organismic whole with definite anatomical body plans [181], or a swarm-being composed of populations of self-replicating genes [182].

In recent decades, this orthodox picture had began to change as more people are becoming aware of the inherently dual nature of life, which, to put it in Deleuze and Guattari's terms, is both molar and molecular [9]. For example, biosemiotics operates with a fundamental "code duality", where an oscillation between the phenotypical pole (the "analog" component of the organism) [13,48], and the genetic structure (the "digital" component) [177,178], is seen by some to constitute the essence of Life [183]. The interplay between various genetic and non-genetic processes in the life and identity of the individual organism has been also acknowledged [184]. Even more striking is the so-called "epigenetic revolution", which aspires to challenge and modify the mechanistic paradigm that has dominated molecular evolutionary biology throughout the twentieth century and after $[185,186]$. Without going into the full details, the main content of all such "revisions" of the modern theory is to point out the need to go beyond the purely Newtonian-Galilean style of mechanistic causality by introducing an element of "meaning" or "sense" into 
biological interactions [13,14,183]. However, again, even after the minor admission that the organism may possess some degree of finalism or awareness of a goal [187], still the general outline of this understanding is that dictated by the orthodoxy of modern mathematical physics: reduction of natural processes to events occurring in spacetime. Recall that the specific sense of the term 'event', which is still widely used in modernism and mainstream science, is nothing but the one originally proposed long time ago within the relativistic physics community, i.e., event there essentially means a mere point in spacetime, the building block or atom out of which worldlines are composed [147]. ${ }^{16}$ It is not really a very different idea compared with prerelativistic physics; for Newton, Laplace, Maxwell, Thomson, we believe, would all agree on the same philosophy of nature entailed by relativistic mechanics, that particularly popular Weltanschauung through which the universe is increasingly seen through the perspective of spacetime, whether static (special relativity) or "dynamic" (gravitation) [188].

In both cases, a difficult question remains: How do you fit an organism into a chainlike cause-and-effect mechanistic outlook, whether deterministic or not? According to the formalist mechanisms of neo-Darwinism [177], something important happens in nature when chance acts on already formed organic bodies, that is, systems complex enough to offer the organism through the thermodynamic fluctuations exerted by the environment a relatively "sophisticated response" [52,189], leading to what biologists call adaptation and modifiability [178,179], which is merely a renaming of one and the same process: the creative advance of nature [76] in response to the posing of a problem that the organism has to solve (the concept of the problematic field of nature as a creative force, see Simondon's work on the philosophy of biology [7]). But how can this happen? "Does the organism think?", here goes the often asked naive question. Bergson [128] and Ruyer [10], for instance, were perfectly happy to suggest that primary consciousness is extended to all matter, not only the human brain and some "higher animals". However, Schopenhauer [190,191], Nietzsche [137], Jung [192], and von Hartman [193] opted for a different mode of what is essentially the same answer: the Unconscious, but now replacing primary consciousness as the formative intelligent principle of the universe.

However, there is a third answer to the same question: What constitutes the universe's bewildering range of complex beings is neither primary consciousness nor the unconscious, but Chaos, that is, the infinite producibility of everything out of everything else $[9,51,194]$. It is this naturalized ontological infinity which supplies the ultimate foundation of the possibility of forming assemblages in nature [9]. That is, Chaos is neither about aggregates nor piles of well-defined elemental parts [100], where the latter two modalities of multiplicity are in fact responsible for setting apart the quantitative mode of being by isolating it from the Qualitative. ${ }^{17}$ What continues to live on in the assemblage, gifting the latter with its true lifeforce, multiplicity, is that peculiar process which, in its innermost being, has always been essentially a non-spatiotemporal becoming, that is, a process already not occurring in spacetime. The very essence of Nature's creativity and nonsubjective intelligence is this formal non-belonging-ness to a larger "container", receptacle-like position space, or geometric topological nets. Such extremely subtle continuous process of evading situatedness in a large container-like receptacle is what we tried to capture by an absolute (naturalized, event ontological) concept like Nonspace for example, which may be viewed as a dynamized inconsistent open whole, a subfield of becoming where multiplicities of event assemblages immanently self-assemble themselves without being embedded into or placed inside a larger transcendental all-encompassing domain. ${ }^{18}$

The idea of Nonspace is hard to fathom without reintroducing a parallel, purely ontological, that is, not merely mathematical, concept of Chaos. In spacetime, Chaos is ineffable. This is related to Chaos being the Unthinkable as understood in the event ontology of nature. In fact, the "irrational" character often attributed to chaos in mainstream science and thinking, especially within analytical philosophy, is precisely due to this ontological tension between Chaos and spacetime: the very ontological concept of Chaos is anti-spacetime in and through; therefore, once one starts by placing Chaos "in" spacetime, all kinds 
of humorous and non-humorous intellectual confusions and misunderstandings would follow. Incidentally, this is also why we agree with Deleuze and Guattari that Chaos, being a non-scientific concept, belongs to philosophy, and that philosophy proper is completely distinct from science [51]. Indeed, For Deleuze and Guattari, the plane of immanence as a section of Chaos belongs to philosophy (concepts), while the plane of organization is where science thrives. In their terminology, concepts and functions are completely distinct, while functions belong exclusively to science [51].

Finally, let us come back to Simondon in order to experiment with the idea of deploying Deleuze and Guattari for the purpose of initiating a reexamination of the three great Simondonian ontological layers of the Real:

1. The living.

2. The intelligent.

3. The self-aware.

In order to isolate these three elements by demarcating them from "inert matter" or passive being (provided something like true "inactive matter" even exists), one must operate outside observable nature altogether, and that includes transcending the perceivable in order to erect a new global immanent order of the Real: Chaos as infinite connective flow bypassing speed, position, nearness, farness, and every similar cartographic or topological concept [51,52]. By moving into higher categories belonging to the abstract realm of the event ontology of nature, the organism is no longer seen as an objective process taking place in spacetime, but rather as an assemblage of events interacting with other event assemblages, the latter sometimes called environment, sometimes other organisms, but most of the time the Other is nothing but the sheer unlimited producibility of Nature, which is also the a defining feature of Chaos. The brain as such is an integral factor of the infinite process of Nature's ownmost inner reconfigurability of its various chains of mutual semiotic intercourse [13], hermeneutic discourse [82], pathways of informational exchange [183,196], and rhizomes of "firing event-neurons" [9], with intelligence as such reduced to that ontologically unconstrained and intrinsicallylly variable connectivity of every event with another. ${ }^{19}$

\section{Modernism on Spacetime and the Organism: Critique and Final Remarks}

So, now, how do you define an organism? Within classical thought, extending up to modernism, the accepted position requires invoking some sort of an all-encompassing "container" or a "universal receptacle" unifying the totality of existing elements (beings) into the being of the organism..$^{20}$ (Obviously, modern science does not put it explicitly this way.) What is crucial for our discussion here is to clearly point out the means by which the alleged "unity" attributed to the organism can be actually enacted in real life. There is no external God or "super-intelligent" being capable of imposing its own divine will above and over the being and the becoming of the organism, hence the well-known difficulty of striking a balanced line between mechanism and vitalism that plagued the history of biology, especially during the last three centuries $[180,200]$. However, whatever the particular theory that science would eventually invoke, we have already stumbled upon a common theme unifying all, otherwise disparate, idealistic modernist theories proposed so far: the existence of spacetime. Not necessarily the physicist's spacetime, nor one particular type of space, say the four-dimensional manifold of Minkowski or Weyl [147,176], but the generic and necessarily abstract Kantian schema of space per se [145], that mathematical order whose roots are in Descartes and Galileo [17], where the essence of being-there (not Dasein [16,31], but, quite literally, being located somewhere) acquires a fundamental ontological status. To a large extent, biologists followed suit, for they appended to the organism its popular veritable, spatiotemporal "label", seeing the living as a "product" of historiological processes of evolution fully enacted within physical space $[177,178]$.

Modernism's idea of Evolution is that evolutionary change invariably occurs within various types of space, say Euclidean "optimization-type" of space [201], non-Euclidean space [202], physical geography [101,102], and geological spacetime [180]. However, the 
key aim of modern science is the enthronement of the present-at-hand [15] by erecting a preferred Subject, to whom the ontological process of presencing is referred, at the topmost metaphysical vantagepoint of a purely spatio-temporally hierarchized architectonic, a pyramidal organization of the various layers of Nature's creations-productions [203], where, in the midst of the flux of a unidirectional causative radiation of Onto-Form, every strata informs and grounds what comes next [9]. Such a transcendental structure of evolution, which continues to exert a deep, subterranean influence on our intellectual generation, keeping etiological thinking alive while nourishing modernism's causalistic thinking-even after the admission of randomness into nature by Darwin [179], Maxwell [204], Boltzmann [205], and quantum theory [206]-is a philosophical framework which, in principle, is broadly compatible with spatiotemporal thinking. Here, there is an order of real events that can always be unpacked into correlated, temporally-ordered links, collectively constituting the ontological chain of final production. Finalism and goal-orientedness are sacrificed on the altar of determinism; complete giveness destroyed by the First Cause; and so on. This is because Causality, according to modernism and Idealism, is a celebration of the infinite joy of a Supreme Creator [56], an anthropomorphic god, a Cartesian Subject [141-143], a Despotic Signifier [207], and so on, where the entire great chain of being is now reduced to the phenomenological givenness of its "first link", conveniently baptized by the Aristotelian directive of The First Mover, or The Platonist One, the Big Bang, which are all supposed to be somehow capable, through the agency of the magical realism of causality and absolute determinism, to survey the Whole by one grand sweeping glance traversing the totality of all existing beings and their unlimited possible and actual connections. ${ }^{21}$ This is the God of traditional thinking, re-embraced by science, and accepted by biologists. However, there is something rotten in the inner foundations of this entire mathematicological discourse of nature. If the organism is produced "in" spacetime, what made the "plan of production in spacetime" as such possible? How is it that organs and relations between cells, tissues, circulatory and nervous systems, just to mention few complex facts, actually acquire that status of being-there, i.e., situated at a spatial position, occupying a location somewhere, and, most importantly, already being "reconfigured" in the ontological mode of ready-at-hand, waiting to enter into various relations with other subsystems, organs, tissues, etc? For, as a matter of fact, even a higher-order ontological mode such as that of being-in-situation, the core "mechanism" behind the functioning of position space, can never be understood without a knowing awareness bringing the situatedness of an entity to self consideration, hence opening up this field of inquiry into that which precedes even the very possibility of being situated, located, positioned, placed, by some other agents.

To recap, Modernism, especially as revealed in the profound philosophical writings [214] of the esoteric Newton [215], is the doctrine of spacetime. What was left for Einstein $[149,216]$, Weyl [151], Eddington [217] was merely to finish what Galileo, Descartes, and Newton had already started in the seventeenth century: the mathematization of nature by implementing a modernist interpretation of Plato's concept of the receptacle [160] where the originally vague and informal Platonic category now acquires an apparent rigor but mainly due to the utilization of mathematical concepts and modes of expressions $[17,43,208]$. Even Kant [218,219], Hegel [54,55], and Husserl [32,220] should be grouped together within this same category, for all of them were Idealists in and through $[15,17,20,146]$, in spite of some "technical differences" between this thinker or that intellectual.

Now what is this spacetime doctrine or ideology all about? It is simply the belief that nature is the sum total of factual beings. The factual, in turn, is defined as that process in possession of an "objective essence", which is nothing but its localaizability in finite regions in spacetime. In other words, what is at stake here is the ability to situate a process with respect to the given location of other processes. The alleged classical relationalism of mechanics is really another expression of the deeper faith in absolute spacetime. Spacetime itself is understood here (and everywhere) as merely space, for modernism as a whole can be distinguished by its love of the spatial and the tendency to "geometrize away" the dynamic in nature. So location, localizability, situation, situatedness, and so on, are all key 
recurring elemental themes frequently encountered in modernist ontologies and scientific outlooks. Being itself is defined in terms of being-in. The idea of being-in is never fully understood as relation, but rather qua substance and essence [56], or qua extension [141-143]. The main problem with this thinking is its consistent failure to dissociate the Real from the subjective $[31,130]$, and hence semiotic and grammatical constructions often gain the upper hand in the battle to control those Idealist ontologies of nature produced within modern science and philosophy. If being-in was approached as a relation (and it was approached this way, though never with great success within mainstream thinking), then one would at least see something new coming out of the concept of Space, say that topological pathway leading us from Leibniz [72,99] to Cantor [89] and culminating in Russell [86]. Well, was space merely the geometry of form? No, for common sense space is still the container per se, the ultimate receptacle, the theater of the world.

We must then go back and reexamine the concepts of space, ontospace, spacetime, position space, geometric space, topological space, ontotopological space, searching for novel modes of thinking Nature and the Real, hopefully moving us completely beyond those disastrous parameters set up by idealism and modernism. A possible new ontology is outlined in the Appendix but the full details should await a future, more comprehensive and detailed treatment. To summarize the event ontology of nature's stand on Idealism and modernism: A modernist, Idealist, or scientist would like us to view nature as the totality of everything that, firstly, is (being-as-presence); and, secondly, is in nature (being-in-space). So, at first, being-through is; then we have the fundamental ontotopological mode of the situatedness of that which has been there in and through situatedness as such. Being is in space, where space has become that formal idealist ontological framework ultimately founding or legitimizing the existence of things [15]. Nature, in this Idealistic view, is a totality, sum, collective gathering of parts and elements heaped into the same place. Beingin-the-sameness of the identical, the recurrent. Parts and bricks amassed into a unit. False unity, not the true Whole or Nature; for the Idealist conceptions of space, spacetime, the Universal Subject, God, are all of the order-type of aggregation, i.e., not belonging in with the ontologically authentic category of multiplicity (Leibniz [72,99,100], Guattari [130,131,195], Ruyer [10]).

\section{The Event Ontology of Nature versus Pantheism}

The reader may have already noticed that many of the thinkers whom we treated in our presentation as, relatively speaking, closer to the program of the event philosophy of nature have been, more or less, also viewed in the secondary literature as either advocating or inclined to one version of pantheism or another. For example, just think of the Ionian physiologists [112,221-223], Cicero [60], Seneca [62], Bruno [70], Spinoza [58], Schelling [73,175,224], Whitehead $[2,74,225]$. There is no doubt that the position of the event ontology of nature is very close - at least in spirit, not necessary the full technical details- to past philosophies of nature such as Ionian physiologism $[8,112,223]$ and Stoicism [60], which are standardly treated by many writers as pantheistic worldviews. Strangely, idealism and materialism both seem to fit into the "pantheistic mold" of philosophy. For example, Hegel is defended by many as a card-carrying pantheist (his concept of Universal Reason is seen as a pantheistic theory of nature). Similarly, Spinzoa is often treated as both an open materialist and pantheistic. One may even extend this list to include ancient religious practices, such as Taoism and possibly some versions of Gnosticism. More confusing, however, is that, in contrast, many writers even deny that any of the above mentioned figures is in fact pantheistic at all! The subject of pantheism and its relation to philosophy remains then extremely controversial and unpopular. Therefore, exact definitions and scholastic arguments and debates on what precisely is meant by pantheism, its true reach, and the precise overall status of this doctorine within ontology, are outside the scope of this article, which is devoted to event ontology, not ontotheology.

Some brief thematic remarks on this complex subject, however, are in order. We should first note that the three successful Abrahamic religions of Judaism, Christianity, and Islam, 
have been extremely hostile to pantheism, basically treating all versions of this approach as heretic, sometimes even not hesitating to employ force to eradicate those suspected of holding sympathies with the pantheistic attitude, e.g., the infamous story of Giordiano Bruno (and many others). This has contributed to a lack of complete understanding of pantheism, especially in relation to monotheism. However, the pantheistic position is a version of theism, hence pantheism should be treated as a chapter of monotheism since both are sharply differentiated by the ontological theory of where God is located in nature. Our view here is that topology and situated-ness lie at the heart of the core technical difference between pantheism on one hand, and other event-based ontological "formats" such as monotheism, polytheism, or even atheism. They all share a tendency to objectify nature by spatializing the latter, a fact that was very clearly stated by Heidegger's critique of the Western tradition scattered in numerous texts and lecture courses.

In contrast to pantheism, the event ontology of nature does not search for a new "location" of God by distributing Him everywhere. Ontotheologically speaking, God is not seen as a Being whose fundamental mode of being is present-at-hand, an ontic modal state of being-there-in-place that, we believe, is an unavoidable consequence of the pantheistic declaration of the identity of God and Nature (God is Nature, or God = Nature). All such pantheistic formulations presuppose a philosophy of Identity, most often through adopting a version of Idealism (Western traditions), or mystical Communion with Nature (some versions of Gnosticism, Hinduism, Sufism, Kabbalism, and others). On the other hand, the event philosophy approach elevates Nature to the status of the total field of that peculiar mode of interconnectedness characteristic of the All [85,101,102], or, Chaos [7,51], which is the infinite virtual horizon of creative continuous created-ness as such. The latter position is non-identatarian by design and hence transcends the entire calculus of difference and identity [19]. God is not seen as identical to a part, or even the totality, of Nature because the very idea of being-in or located-within is rejected as the outcome of spatializing Nature. Nevertheless, it is still open whether the event ontology of nature may develop its own theory of God. Such approaches are not within our immediate concerns in this article, but we may mention that some modern philosophers of nature, such as Whitehead [2] and Zubiri [34], did attempt to develop new ontotheological concepts of deity based on their own understanding of the pervasiveness of the all-encompassing dynamism of Nature as a Whole.

Consider, for instance, the classic posture of "reverence": standing in awe of Nature, being overwhelmed by the majestic machinations of the Natural, the Kantian sublime, and so on. These are some of the most common religious feeling tones characteristic of the various versions of pantheism we happen to know about. However, they should not be seen as traits shared with the event ontology of nature, the latter being, in essence, an attitude that was initially developed from within science, that is, neither from within the framework of traditional theistic religion nor theology. Moreover, Pantheism should not be seen as constituting some sort of a "Religion of Nature" unless one decides to take literary and artistic representations, such as Goethe's and Coleridge's, too literally. If we maintain a strictly philosophical but nontheological frame of reference for the event ontology of nature, then pantheism would automatically stand out as an extreme representative version of monotheism. In fact, pantheism is the exact opposite to the other infamous extreme version: atheism.

Also related to this discussion is pantheism's dicta "God is Near", which echoes (in a different way) the original formula "God is Everywhere". Again, such position contradicts the event ontology of nature since it brings back that present-at-hand mode of spatializing-temporalizing the Natural implicated by the process of declaring that "God exists at some distance from us", which, here, is very small, or even infinitesimal, yet still it is a distance after all, hence positing a metrization of Nature. However, from our new perspective, it is the non-metric topological field of Nature's expansive creativeness as such what is fundamental for the event ontology of nature; in fact, more so in our case than the traditional concepts of deity and godhead themselves. Indeed, the event ontological 
interpretation of nature aims at explaining how different concepts of divinity have formed throughout history. Like Jung's approach [226], the philosophy of nature's objective is to naturalize religion by reducing concepts of deity to abstract and formal materialistic and holistic (nonlocal) structures, such as Simondon's Preindividual, Deleuze and Guattari's Infinite Speed [51], and Heidegger's Fourfold [227].

\section{Conclusions}

We proposed a unified and general approach to philosophy and science, which is dubbed the event ontology of nature. The position takes its departure from multiple sources, including conventional philosophy; French theory, especially its role in the recent postmodernist expansion of the scope of science beyond its orthodox Newtonian framework; and from Heidegger's ontology and ontotheology, his critique of the history and metaphysics in the West, science and the philosophy of nature as manifested through the works of several thinkers before and after Heidegger. Our primary intention had been focused on providing a general, high-level description of the main technical ontological concepts involved in the event ontology program. These include concepts such as Nature's Interconnectedness, the event assemblage, the Whole, the Global, Nonspace, Chaos, and how these naturalistic event-based ontological structures interact with some standard pre-established or existing scientific theories such as Darwinism and modern mathematical physics. A key theme in our text was supplying a critique of the centrality of the spacetime doctrine in modernism, ontology, and science. In particular, we emphasized how while operating from within the general position of the event ontology of nature one can bracket out spacetime by moving into a more fundamental and higher-level structure of reality, such as the framework of events and assemblages, which interact and evolve by participating in Nonspace, a nonspatial ontological framework similar to Deleuze and Guattari's plane of immanence. We also supplied a brief comparison between the event ontology of nature and pantheism due to some possible overlaps in their interpretations, yet we pointed out the main distinction between the two as residing in the former's rejection of concepts of locations, positions, and situatedness essential for the pantheistic approach to nature.

Funding: This research received no external funding.

Conflicts of Interest: The author declares no conflict of interest.

\section{Appendix A. Event Ontology: A Condensed Resume}

The following is a series of propositions on event ontology. In their present form, these propositions were not intended to constitute a complete formal system (some propositions may be derived from others), nor meant to provide an exhaustive exposition of the main principles. Instead, the goal is to equip an interested reader curious about exploring what lies beyond the higher-level discussion found in the main text above with some of the apparatus needed to dig deeper into the subject; though by learning something about the flavor of the technical construction, not the full content of such construction, which will require a much large framework to handle adequately than an appendix (the complete event ontology is currently a work in progress by the author and will be published in future works).

1. Events are dynamical wholes.

2. Space is generated by a dynamic process. (Remark. This is the crux of the emergence of the fundamental theme of ontogenesis in general, its primacy in ontology, and especially the producibility of space).

3. Space is not fundamental but derivative. (Remark. First, spacetime is to be spatialized, as in Weyl's philosophy; then, the non-fundamental character of space is invoked in order to formally establish the derivative character of spacetime itself. It should be noted that clock time in relativistic spacetime is not the same as the more primordial time of the event-as-flow. The latter is more fundamental, and is responsible of producing the derivative and less ontologically basic time of relativistic physics). 
4. Space is created by the collective interaction of events. (Remark. The proper concept of creation here is that of production as in Simondon's ontogenesis. The technical content of collectivity should be captured by a topological/ontotopological approach explicating the transition from local interactions between elements, situated in the neighborhoods of each other, to the global/ontoglobal level of the whole. ${ }^{22}$ ).

5. Each event is a manifold plus a topological flow on this manifold. (Remark. In a more careful mathematical construction of event ontology, one may show that the base manifold itself on which the evental flow is defined is redundant since the group-theoretic action generating a topological flow can be exploited to reconstruct the underlying space itself as in Lie theory or the theory of continuous groups of transformations ${ }^{23}$ ).

6. The flow represents the wholeness of the event, its irreducible global character.

7. The manifold is the matter of the event, its substrate or carrier of action. And this action is conducted via the above mentioned flow.

8. The form of the event is its dynamic law, the transformation group defined on its matter (matter $=$ the underlying phase space or the evental manifold.)

9. The interaction between events is in itself analyzable into form and matter:

(a) The matter component is the interpenetration between the two underlying manifolds of the interacting events.

(b) The form component is the topological compatibility condition between the flows of the two events existing in this overlapping region.

10. Space results from the overall pattern of interactions among all events. The formal structure of this pattern is nothing but the conditions of topological/ontotopological compatibility mentioned above.

11. Space is an emergent phenomenon (the emergent character of space, time, and spacetime has been rediscovered recently in quantum gravity ${ }^{24}$ ).

12. There is a bifurcation of the being-with mode of Being's togetherness into the following two fundamental directions, which, in turn, comport becoming toward two distinguishable chaotic attractor states:

(a) The macroscopic dimension of the world (the molar level): Space.

(b) The microscopic dimension of the world (the molecular level): Events.

13. As a produced molar ontological macro-level of experience, space is linked to the chaotic attractor of the machinic assemblage of organization. This is a zone organically connected to actuality. On the molecular level, however, the chaotic attractor is linked to the intensive microfields associated with events and their assemblages. This is a zone intimately connected to virtuality. ${ }^{25}$

14. The global structure of reality is space at large. The local structure of reality is precisely that ontotopological order determined by the collective pattern of interactions (via conditions of topological compatibility) between the constituting events.

15. The fundamental problem of ontology is to understand the essence of the interrelationship between the local and global.

16. The mystery of metaphysics is the reciprocal interdependence of the whole on the part and the part on the whole. The crux of this relationship, as was envisaged correctly by Aristotle, Leibniz, Russell, and Heidegger, is topological in essence. We prefer the enlarged term ontotopological.

17. The ontological expansion of space (ontospace) is the bridge between mind and nature. The gulf between idealism and materialism is to be closed by adopting the Mach-, Russell-, Whitehead-inspired metaphysical program of seeing elemental events as the ultimate fundamental constitutive bases of reality.

18. In such an approach, ontospace would assume the hidden form of a subtle "aspect of nature" that is still yet to be revealed to the essentially redundant "human intellect", though such "revelation" would occur mainly through nonlogical mathematical abductive thinking and creative nonpersonal artistic imagination. 
19. In event ontology, we don't aim at blocking the way to introspection and phenomenological research, but encourage a revival of materialistic thinking that is more abstract and formalistic than many idealist positions, but without falling into the trap of erecting a global Cartesian or transcendental Subject. This is an approach that we propose to call abstract materialism, which we see as a continuation of ancient modes of thinking, such as those of the pre-Socratic Ionian physiologists, the Stoics, and the Epicureans.

20. Although we describe space as "constructed", it is not our intention to claim that the naturalistic creative process is governed by a mental power. Nor that Nature is enveloped by Nous. The creative process is not even an intellectual principle. We remain agnostic with regard to the ultimate prime dynamic agent lurking behind creativity in Nature.

21. Events are not fictitious nominal placeholders like points and numbers, but essential ontological elements. Understanding their 'being' is the major field of investigation conducted by Heidegger. In the present work, we focus on formal ontology within the context of mathematical philosophy and nature philosophy, following the tradition of Russell, Whitehead, and Deleuze. The work of Heidegger is implicitly presupposed everywhere. It permeates every tangible 21st-century philosophy, or even beyond.

22. The event's matter is not fundamental (against substance ontology). Form is essential being. Since the form of events is the topological dynamic flow, it is conceivable that the evental manifold (matter) may be dispensed with and hence an event can be given only in terms of its dynamical law. But flow is a kind of relation (in fact, a continuum of relations with a topological structure.) Thus, an event is actually a pure relation, and the ultimate stuff of reality is relations.

23. Pure relations as the ontological building blocks of reality. A pure relation is a relation free of its relata (fulfilment of Leibniz's, Russell's, Simondon's, and Deleuze's programmatic dreams ${ }^{26}$ ).

We end then our brief skeletal presentation of event ontology with the above last note on relational being as the essence of becoming, a theme we borrow from Simondon's thought. For more information on the background to event ontology as sketched in this Appendix, see the previous footnotes attached to the propositions, and also the additional remarks provided in Appendix B.

\section{Appendix B. Remarks on the Historical and Conceptual Construction of Event Ontology}

Additional remarks are given below in order to illuminate aspects of the theoretical structure of event ontology as outlined above. Like the skeletal content of Appendix A, the present Appendix is not a comprehensive view on the historical background to event ontology. Throughout the following remarks, we are deliberately selective in choosing specific technical issues to comment on with no intention to provide a comprehensive treatment this time.

1. Leibniz's Monadology [72] is probably the first systematic event ontology we are aware of. However, Leibniz's monad has very little in common with the modern concept of the event described above. Nevertheless, the famous Leibnizian "self-perception" trait of the monad might be interpreted as a form of internal ontotopological flow.

2. The entire concept and theory of production as ontoproduction (ontogenesis) comes from Simondon's thought [7]. See also Deleuze's revival of this Simondonian theme [87,129].

3. On the ontogenesis of space in event ontology, see Russell $[84,86,125]$ and Whitehead [57,77,105]. Auyang's ontology could be considered another more recent example illustrating how spacetime can be generated from a larger cluster of interacting agents [11]. However, note that Auyang's precise technical definition of the event is not the same as Russell's and Whitehead's or the one described in Appendix A.

4. The idea of defining the event as a topological or ontotopological flow is inspired by Schelling [85] and Bergson [126,128], though they did not have the concept of the 
topological flow (dynamic system [246]) at their time. They grasped the event as aktions and duration, respectively. Bergson's duration influenced Whitehead's later work, especially Process and Reality [2]. Strangely though, Whitehead's formal ontology, masterfully worked out in his earlier-and much shorter-text, Concept of Nature [57], does not think the event as a purely dynamic whole; instead, and like Russell [86] on this matter, Whitehead's theory makes the event looks more like a "spacetime subdomain" (the definition of the event in Russell and Whitehead, in general, is never spelled out very clearly even in their most technically complex texts).

5. Both Russell and Whitehead were misled, through their respective interpretations of Einstein's general relativity [86,247], into defining the event as a "block of spacetime", apparently imagining that in this manner, and following Weyl's earlier suggestion $[147,151,152]$, their event concept, thus defined, somehow becomes "fully dynamized". The construction outlined in Appendix A rejects this approach, seeking instead a more radical definition of the event as a topological flow in the sense of dynamic system theory where the flow's time is primordial and precedes all other types of time (however, the final construction would seek to somehow reformulate the topological definition in an "ontotopological" manner. Such details are outside the scope of this Appendix).

6. On the other hand, we note that the formulation of event ontology outlined above may in turn suggest an alternative version based on separating time from space by defining the event as a topological flow with "external time". However, this "external time" is neither the clock time of relativistic physics nor the thermodynamic time of cosmology [189]. It is a more primordial "evental time" which underlies all other types of time, whether physical, psychological, social, and so on.

7. The term 'ontotopology' is proposed here in order to try to gather in a systematic manner a sorely needed subfield of "postmodern mathematics" required for the completion of the program of the event ontology of nature. In our event philosophy, the term ontotopology means topology constructed, defined, and consumed for purely ontological reason; or doing topology in and through ontology. The ontotopological is an ontological category constructed using methods borrowed from general (settheoretic) topology. Russell [244] and Hausdorff [229] are precursors to ontotopology though they never used the term nor saw its full potential.

8. The concept of topological compatibility conditions is inspired by Guattari's concept of "conditions of consistency" [195], which was worked out (with Deleuze) as a way to determine how a multiplicity (realized by an abstract machine as a concrete machinic assemblage) may hold its constituents together [9]. However, it does not seem to us that their ontology is an ontology of event assemblages. Their multiplicities appear to be comprised of more generic "elements" or "things", such as particles, signs, particlesigns, molar strata, molecules, and so on. They do not operate with the technical concept of event defined as an ontotopological flow.

The above remarks only point out certain directions in our still evolving understanding of the historical background to event ontology, which, we believe, has not been worked out in details yet. On the conceptual level, what is still needed is a complete and substantial development of new domains of research where we move from (i) space to ontospace, (ii) from topology to ontotopology, and (iii) from genesis to ontogenesis. The last transition was initiated and substantiated by the works of Simondon [7,8,115]. The first two, however, are still open areas of research. Future progress in event ontology, we believe, will depend on closing this gap.

\section{Notes}

As will be explained shortly, we believe that neither ontotheology nor the event ontology of nature (to be introduced shortly) should be viewed as ways to revive theology through ontology. However, as some of the references given in the Introduction suggest, several authors have indeed attempted to achieve precisely that goal. Our position will be that conventional theological 
concepts need to be either rejected or drastically revised in order to integrate them with the truly postmodernist and naturalistic position of event ontology.

2 A possible explanation of why the Heideggerian project of ontotheology had been negative and critical might probably be located in the fact that the prevailing modern Galilean-Cartesian science complex [28], together with the parallel and closely related social system of merchant/industrial capitalism [29], had formulated a worldview of nature through which the human dimension has been reduced to a minimal position of little importance, while the totalizing mechanization of nature and society through the machination of science and capital was allowed to reach exaggerated measures [30]. Reintroducing a form of the human that avoids falling back into Cartesianism and Idealism then required a fully-fledged destruction of the entire history of that particular brand of western metaphysics that originally lead to Descartes and Galileo. This is the path first taken by the early Heidegger [31]. On the other hand, thinkers such as Husserl sought the same goal but by in fact re-founding Cartesianism on new phenomenological foundations [32]. We reject the Husserlian approach and align ourselves instead with Heidegger's overall path.

3 The key idea is that ontotheology is traditionally viewed as the critique of all ontologies of presence. It is important, however, to note that the later Heidegger rejected the very term ontology as such [30], and in fact eventually stopped using the expression being altogether. He even refused to view himself as a "philosopher", preferring instead the epithet guide [41,42]. From this perspective, Heidegger's negative use of ontotheology as a limitative concept came to dominate subsequent discussions of the topic. From our own view, though, it is debatable whether Heidegger's postmytaphysical mood was able to actually overcome ontology as such. It is true that Heidegger destroyed the ontology of presence, especially the long tradition of Idealism in Western metaphysics, but that does not necessarily imply rejecting ontology as such. The standard definition of ontology given in various teaching-based lecture courses by Heidegger, which defines the field as the discourse on being-as-present [15,17,43], can or even should be enlarged in scope and expanded in content by utilizing the completely new and original ontological categories developed in Heidegger's other texts such as Being and Time [31] and On the Event [30]. It is quite remarkable that Heidegger himself chose not to pursue this direction in his later years, preferring instead to concentrate on his rather "exotic" poetic approach to Nature based on Hölderlin [44,45].

4 We will not provide detailed and complete technical definitions for each of these event-ontological concepts; only the general thrust of their generic significations will be suggested in the various sections to follow. However, see Appendices A and B for some summary technical overview. For our immediate purposes in the main text of this article, few things need to be highlighted. First, note that there is no universal agreement on the meaning or the sense alloted to each of the above mentioned terms. For instance, the ancient concept of Chaos was reexported into modernity, where it was filtered by mathematics and reshaped by science in order to be rebranded as a special, highly complex solution of nonlinear differential equations [47]. However, in later times one finds that such exotic theory of chaos-as-a-special-mathematical-solution had been considerably enlarged in scope and essence, mainly through postmodernism, where the concept was reappropriated for the purpose of constructing a more comprehensive philosophical framework encompassing wider ontological/metaphysical constructs such as chreods [48-50], infinite speed [51], and nature's createdness [52]. It is in these latter expansions of the concept of Chaos where we feel more at home with respect to our proposed program of the event ontology of nature.

5 See Whitehead on the positive sense of the term 'speculative' in the philosophy of nature [74-77]. Also, he explicitly admitted the limitation of science and the need to introduce speculative elements into natural philosophy [2]. Needless to say, Whitehead's position has been enormously influential in both physics [78] and the philosophy of nature [79].

6 On the idea of ontological jurisprudence in Kant's project, see Heidegger [17], Deleuze [80], Gadamer [81,82], and Cassirer [83]. According to some of these thinkers, negative critique in Kantian philosophy need not be non-constructive. From our perspective, it is not clear why critical philosophy should always be considered more "scientific" or "methodological" than speculative (natural) philosophy. The example of Whitehead [2] (and Russell [84]) demonstrates how one philosophy can simultaneously illuminate epistemological issues in science and be metaphysically bold and innovative (that is, "speculative" in the positive sense mentioned above).

7 The article itself is designed such that an appreciation of the main text might be attained without necessarily reading the Appendix. However, readers interested in learning more about event ontology may benefit from the expanded treatment given in the two Appendices and the additional references supplied therein, especially in Appendix B and also the footnotes to Appendix A.

8 At this stage it might be important to say few words about our choices of highlighted points of contact selected from within the past history of the philosophical movement here summoned under the programmatic banner of the "event ontology of nature", especially in regard to our mentioning of the names of Leibniz and Schelling within this context, which may raise few eyebrows. The reader might wonder whether these two thinkers could be treated in an event-based ontological framework where the Heideggerian critique has already rejected idealism (and so did postmodernism). Since Leibniz and Schelling are sometimes linked with Idealism (Schelling more so than Leibniz), the question is whether the Leibnizian and Schellingian categories are really needed here. Our response is that when it comes to Schelling, we agree that he did advocate an early form of universal Idealism that was later famously adopted and deployed by Hegel [55]. However, it also should be borne in mind that Schelling's main idealist texts [53] differ substantially from his more naturalistic or "materialistic" formulations found in the philosophy of nature texts $[85,95]$. While a Hegelian ontology of universal idealism modeled on consciousness can be linked to some formulations by Schelling $[18,106,107]$, one cannot dismiss the latter's other, more radical, ontologies, namely those of the 
event (what he called aktions [85]). In any case, it is with the second, less popular, materialist dimension of Schelling's thought where we find a broader agreement in the event ontology of nature. Regarding Leibniz, the situation is more complicated due to the fact that his work was not fully canonized and edited by the time of his death, leading to the well-known difficulty of assessing which text is the most important or even relevant. Nevertheless, Leibniz can certainly be interpreted as a contributor to a materialist ontology of the world, in the tradition of Spinoza and more recently Althusser [108,109]. A good place to learn about this scope can be found in the texts on Leibniz by Russell [110] and Deleuze [111]. For the entire material discussed in this note, see also the different but related discussion given in Appendix B.

9 For more information on the technical sense in which the term 'devolvement' is currently understood in the ontology of nature, see Bohm's text [122]. Roughly speaking, the paired concepts folding/unfolding could be invoked to analyze a process of "evolving/deevolving," where form is manifested in and through rather complex topological folding/re-folding operations. The later are busy at work, shaping nature, though to us they are mostly invisible, and are capable of both folding-in or folding-out (unfolding) while constructing or deconstructing molar strata and assemblages [111]. This concept is deeply connected with mathematical chaos [123]. In Deleuze and Guattari's ontology, one possible interpretation of the Bohmian processes of development and devolvement (winding up and winding down) is by linking them to the processes of the deterritorialization of the Earth [9] and the de-coding of the Socius [124].

10 Cf. Section 4.

11 We should note though that Simondon was in fact critical of many aspects of Bergsonism [7]. On the other hand, Deleuze, who was deeply influenced by both Bergson [134] and Simondon [135], tended to present their respective systems as if they are coherent or even mutually consistent $[87,129]$.

12 It is probably for this reason that Heidegger was not occupied with the so-called "problem of the body". Contrary to what is mentioned sometimes in the secondary literature, Heidegger did not neglect the body but intentionally avoided emphasizing bodily aspects because he saw, correctly in our opinion, that any preoccupation with such problematic is a potential backdoor or a Trojan horse permitting the despised doctrine of Idealism to re-invade philosophy. The principal example in Heidegger's mind is most likely Nietzsche, whose "physiological approach" to philosophy [137] Heidegger rejected as Idealism-via-Biologism [139,140]. Cf. Appendix A.

14 See also Appendix B for additional information on the historical background to event ontology.

15 Cf. Section 7.

16 Cf. Section 4.

17 See the remarkable analysis of the subtle differences between various modes of multiplicities in Leibniz's correspondence with Arnauld, where the ontological distinction between aggregates (a quantitative concept) and, in our terminology, assemblages or "authentic multiplicities" (a topological concept) is clearly stated [100]. Essentially the same ontological theme appears to have been picked up again by Guattari $[130,195]$ and further developed in Deleuze and Guattari [9].

\section{Cf. Appendix A.}

19 On the theory of the brain, see Deleuze's texts on Cinema [197,198] and his last collaboration with Guattari [51]. On the ontological relation between mind and nature, see Bateson [13,14], who is fundamental for any project for the ontology of nature. In general, the relation between noology and ontology is a complex one and will not be addressed in detail here. Nevertheless, we state our opinion that noology should eventually be fully absorbed into a naturalistic ontology of an event-based framework of creativity, which, in contrast to traditional theology or Idealistic ontologies, is completely immanent and anti-transcendentalist in and through. On the concept of immanence in the philosophy of nature, see Deleuze's late text Pure Immanence: A Life [199].

20 Cf. Sections 4 and 5.

21 For a penetrating critique of the various concepts of causality found in Schopenhauer and Leibniz, see Heidegger's texts on the principle of sufficient reason and logic [43,208]. As part of his parallel critique of Kant $[15,145,146]$, Heidegger considered causality as an essential component of the heritage of Idealism (what he called the philosophies of presence) that dominated Western metaphysics since its First Beginning in the Greek inception of Western thinking [30,90]. In our own interpretation, the event ontology of nature as a research program antagonistic to Idealism must then reject the fundamental ontological status of causality and replace it (like spacetime) with a more primordial concept. One promising such attempt is Russell's unorthodox concept of causality, which is closely linked to his event ontology, developed in texts such as [84,86,125], but see also Reichenbach's interesting approach to causality in [209-212]. Both Russell and Reichenbach, now it appears to us, had developed original distinctive theories of causality that are outside conventional spacetime. For Russell, this was achieved by deploying event assemblages in order to produce spacetime itself [213], where causality is defined at the level of the events themselves, not their derivative (later) spacetime [86]. For Reichenbach, the formulation is less obvious because in that approach he moved beyond traditional spacetime proper by introducing probability spaces and purely stochastic assemblages (stochastic superspace) [210].

22 See Lautman's masterful analysis of the relation between the local and the global as reconstructed from the theory of differential equations and group theory [228]. General topology in mathematics is the principal field focused on this problem at the very abstract level of set theory [229]. Within a more "concrete" framework, the local/global dialectic can be reformulated using the 
language — and setting — of Lie theory [230]. These technical instructions on how to move from a local level to the more global system are fundamental for event ontology.

On the mathematical use of Lie theory in philosophy, see [228,231]. On Lie theory itself, see [230,232-234]. The concept of topological flows is treated in various places in literature [235-237].

On the production of spacetime in quantum gravity, see $[170,238,239]$. Interestingly, this has been already predicted philosophically several decades before in the works of various thinkers such as Russell and Whitehead [213].

On the ontological theory of the virtual and actual, see Leibniz [72], Fichte [240], Bergson [126-128], Simondon [7], Ruyer [10], Whitehead [241], Deleuze [129], who don't use the same technical terms when they refer to similar concepts. (In our opinion, Heidegger's ontological difference $[19,31]$ might be reinterpreted as a contribution to the ontology of virtual being, though this interpretation has not been convincingly carried out by anyone yet). The machinic-chaotic attractor construction and the molar/molecular ontology are based on Deleuze and Guattari's model developed in the Challenger Lecture in A Thousand Plateau [9]. See in particular Murray's original interpretation and expansion of this model [242].

26 On the primacy of relations, see Russell [155-157,243,244], Simondon [7,8], and Deleuze [245]. The Definition of the event as a pure ontotopological flow fulfils this requirement of the primacy of relations. Note that the event's "base manifold" can be recovered from the relational structure of the transformational law of the topological/ontotopological flow, so even the "relata" of the transformation flow group (in this case the elements of the underlying geometrical space or manifold on which the group acts) are embedded into the very structure of the relation itself. It is as if becoming begets being, an old idea in philosophy anyway though it receives an interesting independent confirmation in the mathematical philosophy and fundamental metaphysics of event ontology.

\section{References}

1. Feyerabend, P. Philosophy of Nature; Polity Press: Cambridge, UK; Medford, MA, USA, 2018.

2. Whitehead, A. Process and Reality: An Essay in Cosmology; Free Press: New York, NY, USA, 1978.

3. Heiden, G. Ontology after Ontotheology: Plurality, Event, and Contingency in Contemporary Philosophy; Duquesne University Press: Pittsburgh, PA, USA, 2014.

4. Dillard, P. Non-Metaphysical Theology after Heidegger; Palgrave Macmillan US Imprint Palgrave Macmillan: New York, NY, USA, 2016.

5. Westphal, M. Overcoming Onto-Theology: Toward a Postmodern Christian Faith; Fordham University Press: New York, NY, USA, 2001.

6. Schrijvers, J. Ontotheological Turnings?: The Decentering of the Modern Subject in Recent French Phenomenology; State University of New York Press: Albany, NY, USA, 2011.

7. Simondon, G. Individuation in Light of Notions of form and Information, Part I; University of Minnesota Press: Minneapolis, MN, USA, 2020.

8. Simondon, G. Individuation in Light of Notions of form and Information, Part II; University of Minnesota Press: Minneapolis, MN, USA, 2020.

9. Deleuze, G.; Guattari, F. A Thousand Plateaus: Capitalism and Schizophrenia; University of Minnesota Press: Minneapolis, MN, USA, 1987.

10. Ruyer, R. Neofinalism; University of Minnesota Press: Minneapolis, MN, USA, 2016.

11. Auyang, S. How Is Quantum Field Theory Possible; Oxford University Press: New York, NY, USA, 1995.

12. Unger, R.; Smolin, L. The Singular Universe and the Reality of Time: A Proposal in Natural Philosophy; Cambridge University Press: Cambridge, UK, 2014.

13. Bateson, G. Steps to an Ecology of Mind; University of Chicago Press: Chicago, IL, USA, 2000.

14. Bateson, G. Mind and Nature: A Necessary Unity; Hampton Press: Cresskill, NJ, USA, 2002.

15. Heidegger, M. What Is a Thing? H. Regnery Co: Chicago, IL, USA, 1968.

16. Heidegger, M. History of the Concept of Time: Prolegomena; Indiana University Press: Bloomington, IN, USA, 1985.

17. Heidegger, M. The Basic Problems of Phenomenology; Indiana University Press: Bloomington, IN, USA, 1988.

18. Heidegger, M. Hegel's Phenomenology of Spirit; Indiana University Press: Bloomington, IN, USA, 1994.

19. Heidegger, M. Identity and Difference; University of Chicago Press: Chicago, IL, USA; London, UK, 2002.

20. Heidegger, M. Basic Writings: From Being and Time (1927) to The Task of Thinking (1964); Harper Perennial Modern Thought: New York, NY, USA, 2008.

21. Heidegger, M. Pathmarks; Cambridge University Press: Cambridge, UK; New York, NY, USA, 1998.

22. Wolfe, J. Heidegger and Theology; Bloomsbury T \& T Clark: London, UK; New York, NY, USA, 2014.

23. Wolfe, J. Heidegger's Eschatology: Theological Horizons in Martin Heidegger's Early Work; Oxford University Press: Oxford, UK, 2015.

24. Buren, J. The Young Heidegger: Rumor of the Hidden King; Indiana University Press: Bloomington, IN, USA, 1994.

25. Moore, I. Eckhart, Heidegger, and the Imperative of Releasement; State University of New York Press: Albany, NY, USA, 2019.

26. Sweeney, C. Sacramental Presence after Heidegger: Onto-Theology, Sacraments, and the Mother's Smile; Cascade Books: Eugene, OR, USA, 2015.

27. Thomson, I. Heidegger on Ontotheology: Technology and the Politics of Education; Cambridge University Press: Cambridge, UK; New York, NY, USA, 2005.

28. Feyerabend, P. Against Method; Verso: London, UK; New York, NY, USA, 2010. 
29. Braudel, F. Civilization and Capitalism: 15th-18th Century (Volume 3: The Perspective of the World); University of California Press: New York, NY, USA, 1992.

30. Heidegger, M. Contributions to Philosophy: Of the Event; Indiana University Press: Bloomington, IN, USA, 2012.

31. Heidegger, M. Being and Time; HarperPerennial/Modern Thought: New York, NY, USA, 2008.

32. Husserl, E. The Crisis of European Sciences and Transcendental Phenomenology: An Introduction to Phenomenological Philosophy; Northwestern University Press: Evanston, IL, USA, 1970.

33. Armitage, D. Heidegger's Pauline and Lutheran Roots; Palgrave Macmillan: New York, NY, USA, 2016.

34. Zubiri, X. Dynamic Structure of Reality; University of Illinois Press: Urbana, IL, USA, 2003.

35. Zubiri, X. On Essence; Catholic University of America Press: Washington, DC, USA, 1980.

36. Zubiri, X. Man and God; University Press of America: Lanham, MD, USA, 2009.

37. Zubiri, X. Fundamental Problems of Western Metaphysics; University Press of America: Lanham, MD, USA, 2010.

38. Zubiri, X. Nature, History, God; University Press of America: Washington, DC, USA, 1981.

39. Jonas, H. The Phenomenon of Life: Toward a Philosophical Biology; Northwestern University Press: Evanston, IL, USA, 2001.

40. Jonas, H. The Gnostic Religion: The Message of the Alien God and the Beginnings of Christianity; Beacon Press: Boston, MA, USA, 2001.

41. Heidegger, M. Country Path Conversations; Indiana University Press: Bloomington, IN, USA, 2016.

42. Heidegger, M. On the Way to Language; Harper \& Row: San Francisco, CA, USA, 1982.

43. Heidegger, M. The metaphysical Foundations of Logic; Indiana University Press: Bloomington, IN, USA, 1992.

44. Heidegger, M. Holderlin's Hymns Germania and The Rhine; Indiana University Press: Bloomington, IN, USA, 2014.

45. Heidegger, M. Elucidations of Holderlin's Poetry; Humanity Books: Amherst, NY, USA, 2000.

46. Mikki, S. Homo Philosophicus: Reflections on the Nature and Function of Philosophical Thought. Philosophies $2021,6,77$. [CrossRef]

47. Prigogine, I. From Being to Becoming: Time and Complexity in the Physical Sciences; W.H. Freeman: San Francisco, CA, USA, 1980.

48. Waddington, C.H. Strategy of the Genes; Taylor \& Francis: Abingdon, UK, 2015.

49. Thom, R. Mathematical Models of Morphogenesis; Ellis Horwood Halsted Press: Chichester, UK; New York, NY, USA, 1983.

50. Thom, R. Structural Stability and Morphogenesi: An Outline of a General Theory of Models; Addison-Wesley Pub: Reading, MA, USA, 1989.

51. Deleuze, G.; Guattari, F. What Is Philosophy? Columbia University Press: New York, NY, USA, 1994.

52. Prigogine, I.; Stengers, I. Order Out of Chaos: Man's New Dialogue with Nature; Bantam Books: New York, NY, USA, 1984.

53. Schelling, F. System of Transcendental Idealism (1800); University Press of Virginia: Charlottesville, WV, USA, 1978.

54. Hegel, G. Hegel's Philosophy of Nature: Being Part Two of the Encyclopaedia of the Philosophical Sciences (1830)7; Clarendon Press: Oxford, UK; New York, NY, USA, 2004.

55. Hegel, G. The Science of Logic; Cambridge University Press: Cambridge, UK; New York, NY, USA, 2010.

56. Aquinas, T. Summa Theologica (Complete in a Single Volume); Coyote Canyon Press: Claremont, CA, USA, 2018.

57. Whitehead, A. The Concept of Nature: The Tarner Lectures Delivered in Trinity College, November 1919; Cambridge University Press: Cambridge, UK, 2015.

58. Spinoza. Ethics; Penguin Books: London, UK; New York, NY, USA, 1996.

59. Aristotle. Metaphysics; Hackett Publishing Company: Indianapolis, IN, USA; Cambridge, UK, 2016.

60. Cicero, M. The Nature of the Gods; Oxford University Press: Oxford, UK; New York, NY, USA, 2008.

61. Seneca, L. Letters on Ethics; The University of Chicago Press: Chicago, IL, USA, 2015.

62. Seneca, L. Natural Questions; University of Chicago Press: Chicago, IL, USA, 2010.

63. Plotinus. The Enneads; Cambridge University Press: Cambridge, UK, 2018.

64. Proclus. The Commentaries of Proclus on the Timaeus of Plato: In Five Books, Containing a Treasury of Pythagoric and Platonic Physiology, Translated by Thomas Taylor; CreateSpace: Scotts Valley, CA, USA, 2012.

65. Proclus. The Elements of Theology; Clarendon Press Oxford University Press: New York, NY, USA, 1992.

66. Avicenna. The Metaphysics of The Healing; Brigham Young University Press: Provo, UT, USA, 2004.

67. Bloch, E. Avicenna and the Aristotelian Left; Columbia University Press: New York, NY, USA, 2019.

68. Averroes. Averroes' Tahafut al-Tahafut: The Incoherence of the Incoherence; Gibb Memorial Trust: London, UK, 2008.

69. Averroes. Averroes: On the Harmony of Religion and Philosophy; Printed for the trustees of the E.J.W. Gibb Memorial and published by Luzac: London, UK, 1961.

70. Bruno, G. Cause, Principle, and Unity: Five Dialogues; Greenwood Press: Westport, CT, USA, 1976.

71. Scotus, J. Philosophical Writings: A Selection; Hackett Pub. Co: Indianapolis, IN, USA, 1987.

72. Leibniz, G. Philosophical Papers and Letters; D. Reidel Pub. Co: Dordrecht, Holland; Boston, MA, USA, 1976.

73. Schelling, F. Bruno, or, On the Natural and the Divine Principle of Things; State University of New York Press: Albany, NY, USA, 1984.

74. Whitehead, A. Symbolism: Its Meaning and Effect; Fordham University Press: New York, NY, USA, 1985.

75. Whitehead, A. The Function of Reason; Beacon Press: Boston, MA, USA, 1958.

76. Whitehead, A. Adventures of Ideas; Macmillan Co: New York, NY, USA, 1933.

77. Whitehead, A. Science and the Modern World; Free Press: New York, NY, USA, 1967.

78. Eastman, T. (Ed.) Physics and Whitehead: Quantum, Process, and Experience; State University of New York Press: Albany, NY, USA, 2003. 
79. Stengers, I. Thinking with Whitehead: A Free and Wild Creation of Concepts; Harvard University Press: Cambridge, MA, USA; London, UK, 2011.

80. Deleuze, G. Kant's Critical Philosophy: The Doctrine of the Faculties; University of Minnesota Press: Minneapolis, MN, USA, 1984.

81. Gadamer, H. Philosophical Hermeneutics; University of California Press: Berkeley, CA, USA, 1976.

82. Gadamer, H. Truth and Method; Continuum: New York, NY, USA, 2004.

83. Cassirer, E. Kant's Life and Thought; Yale Univ. Press: New Haven, CT, USA, 1983.

84. Russell, B. Human Knowledge: Its Scope and Value; Taylor \& Francis: Abingdon, UK, 2016.

85. Schelling, F. First Outline of a System of the Philosophy of Nature; State University of New York Press: Albany, NY, USA, 2004.

86. Russell, B. The Analysis of Matter; Spokesman: Nottingham, UK, 2007.

87. Deleuze, G. Logic of Sense; Bloomsbury Academic: London, UK, 2015.

88. Heidegger, M. Bremen and Freiburg Lectures: Insight into That Which Is and Basic Principles of Thinking; Indiana University Press: Bloomington, IN, USA, 2012.

89. Cantor, G. Contributions to the Founding of the Theory of Transfinite Numbers; Dover Publications: New York, NY, USA, 1955.

90. Heidegger, M. Mindfulness; Continuum: London, UK; New York, NY, USA, 2006.

91. Mikki, S. Aesthetic Theory and the Philosophy of Nature. Philosophies 2021, 6, 56. [CrossRef]

92. Marcuse, H. Hegel's Ontology and the Theory of Historicity; MIT Press: Cambridge, MA, USA, 1987.

93. Husserl, E. Logical Investigations: Volume 1; Routledge: London, UK; Taylor \& Francis Group: New York, NY, USA, 2001.

94. Husserl, E. Logical Investigations: Volume 2; Routledge: London, UK; Taylor \& Francis Group: New York, NY, USA, 2001.

95. Schelling, F. Ideas for a Philosophy of Nature as Introduction to the Study of This Science: 1797; Cambridge University Press: Cambridge, UK; Cambridgeshire, UK; New York, NY, USA, 1988.

96. Humboldt, A. Views of Nature; The University of Chicago Press: Chicago, IL, USA; London, UK, 2016.

97. Humboldt, A. Selected Writings; Alfred A. Knopf: New York, NY, USA, 2018.

98. Wulf, A. The Invention of Nature: Alexander von Humboldt's New World; Alfred A. Knopf: New York, NY, USA, 2015.

99. Leibniz, G. The Labyrinth of the Continuum: Writings on the Continuum Problem, 1672-1686; Yale Univ. Press: New Haven, CT, USA, 2001.

100. Leibniz, G. The Leibniz-Arnauld Correspondence: With Selections from the Correspondence with Ernst, Landgrave of Hessen-Rheinfels; Yale University Press: New Haven, CT, USA, 2016.

101. Humboldt, A. Cosmos: Sketch of a Physical Description of the Universe: Volume 1; Cambridge University Press: Cambridge, UK, 2010.

102. Humboldt, A. Cosmos: Sketch of a Physical Description of the Universe: Volume 2; Cambridge University Press: Cambridge, UK, 2010.

103. Mach, E. The Analysis of Sensations, and the Relation of the Physical to the Psychical; Dover Publications: New York, NY, USA, 1959.

104. Mach, E. The Science of Mechanics: A Critical and Historical Account of Its Development; Open Court: LaSalle, IL, USA, 1974.

105. Whitehead, A. An Enquiry Concerning the Principles of Natural Knowledge; Cosimo: New York, NY, USA, 2007.

106. Heidegger, M. Hegel; Indiana University Press: Bloomington, IN, USA, 2015.

107. Heidegger, M. Hegel's Concept of Experience: With a Section from Hegel's Phenomenology of Spirit; Harper \& Row: San Francisco, CA, USA, 1989.

108. Althusser, L. The Humanist Controversy and Other Writings: 1966-67; Verso: London New York, NY, USA, 2003.

109. Althusser, L. Philosophy of the Encounter: Later Writings (1978-87); Verso: London New York, NY, USA, 2006.

110. Russell, B. A Critical Exposition of the Philosophy of Leibniz; Routledge: London, UK, 1992.

111. Deleuze, G. The Fold: Leibniz and the Baroque; University of Minnesota Press: Minneapolis, MN, USA, 1993.

112. Nietzsche, F. The pre-Platonic Philosophers; University of Illinois Press: Urbana, IL, USA, 2001.

113. Lovelock, J. The Vanishing Face of Gaia: A Final Warning; Basic Books: New York, NY, USA, 2009.

114. Lovelock, J. The Ages of GAIA: A Biography of Our Living Earth; Norton: New York, NY, USA, 1995.

115. Simondon, G. On the Mode of Existence of Technical Objects; Univocal Publishing, University of Minnesota Press: Minneapolis, MN, USA, 2017.

116. Scott, D. Gilbert Simondon's Psychic and Collective Individuation: A Critical Introduction and Guide; Edinburgh University Press: Edinburgh, UK, 2014.

117. Combes, M. Gilbert Simondon and the Philosophy of the Transindividual; MIT Press: Cambridge, MA, USA, 2013.

118. Mills, S. Gilbert Simondon: Information, Technology, and Media; Rowman \& Littlefield International: London, UK, 2016.

119. Bardin, A. Epistemology and Political Philosophy in Gilbert Simondon: Individuation, Technics, Social Systems; Springer: Dordrecht, The Netherlands, 2015.

120. Boever, A.; Murray, S.S.Y.; Roffe, J. (Eds.) Gilbert Simondon: Being and Technology; Edinburgh University Press: Edinburgh, UK, 2012.

121. Ruyer, R. The Genesis of Living Forms; Rowman \& Littlefield Publishers: London, UK; New York, NY, USA, 2020.

122. Bohm, D. Wholeness and the Implicate Order; Routledge: London, UK; New York, NY, USA, 2002.

123. Gilmore, R. The Topology of Chaos: Alice in Stretch and Squeezeland; Wiley-VCH John Wiley distributor: Weinheim, Germany; Chichester, UK, 2011.

124. Deleuze, G.; Guattari, F. Anti-Oedipus: Capitalism and Schizophrenia; University of Minnesota Press: Minneapolis, MN, USA, 1983.

125. Russell, B. Our Knowledge of the External world: As a Field for Scientific Method in Philosophy; Routledge: London, UK; New York, NY, USA, 2009. 
126. Bergson, H. Time and Free Will: An Essay on the Immediate Data of Consciousness; Harpars: New York, NY, USA, 1960.

127. Bergson, H. Matter and Memory; Zone Books: New York, NY, USA, 1988.

128. Bergson, H. Creative Evolution; University Press of America: Lanham, MD, USA, 1984.

129. Deleuze, G. Difference and Repetition; Columbia University Press: New York, NY, USA, 1994.

130. Guattari, F. The Machinic Unconscious: Essays in Schizoanalysis; Semiotext(e) Distributed by the MIT Press: Los Angeles, CA, USA; Cambridge, MA, USA, 2011.

131. Guattari, F. Schizoanalytic Cartographies; Bloomsbury: London, UK; New York, NY, USA, 2013.

132. Dosse, F. Gilles Deleuze E Felix Guattari: Intersecting Lives; Columbia University Press: New York, NY, USA, 2010.

133. Bifo, F. Flix Guattari: Thought, Friendship, and Visionary Cartography; Palgrave Macmillan: London, UK, 2014.

134. Deleuze, G. Bergsonism; Zone Books: New York, NY, USA, 1988.

135. Roffe, J. Deleuze's Philosophical Lineage I; Edinburgh University Press: Edinburgh, UK, 2009.

136. Nietzsche, F. The Will to Power: Selections from the Notebooks of the 1880s; Penguin classics, Penguin Books: London, UK, 2017.

137. Nietzsche, F. The Will to Power; Random House: New York, NY, USA, 1967.

138. Nietzsche, F. Writings from the late Notebooks; Cambridge University Press: Cambridge, UK; New York, NY, USA, 2003.

139. Heidegger, M. Nietzsche: Volumes 1 and 2 (Volume 1: The Will to Power as Art, Volume 2: The Eternal Recurrence of the Same); HarperSanFrancisco: San Francisco, CA, USA, 1991.

140. Heidegger, M. Nietzsche: Volumes 3 and 4 (Volume 3: The Will to Power as Knowledge and as Metaphysics; Volume 4: Nihilism); HarperSanFrancisco: San Francisco, CA, USA, 1991.

141. Descartes, R. The Philosophical Writings of Descartes: Volume 1; Cambridge University Press: Cambridge, UK, 1985.

142. Descartes, R. The Philosophical Writings of Descartes: Volume 2; Cambridge University Press: Cambridge, UK, 1985.

143. Descartes, R. The Philosophical Writings of Descartes: Volume 3 (The Correspondence); Cambridge University Press: Cambridge, UK, 1993.

144. Grosz, E. The Incorporeal: Ontology, Ethics, and the Limits of Materialism; Columbia University Press: New York, NY, USA, 2017.

145. Heidegger, M. Kant and the Problem of Metaphysics; Indiana University Press: Bloomington, IN, USA, 1962.

146. Heidegger, M. The Question Concerning the Thing: On Kant's Doctrine of the Transcendental Principles; Rowman \& Littlefield International Ltd.: London Lanham, MD, USA, 2018.

147. Weyl, H. Space, Time, Matter; Dover Publications: New York, NY, USA, 1952.

148. Descartes, R. Discourse on Method, Optics, Geometry, and Meteorology; Hackett Pub: Indianapolis, IN, USA, 2001.

149. Einstein, A. Ideas and Opinions; Crown Trade Paperbacks: New York, NY, USA, 1995.

150. Pesic, P. (Ed.) Beyond Geometry: Classic Papers from Riemann to Einstein; Dover Publications: Mineola, NY, USA, 2007.

151. Weyl, H. Philosophy of Mathematics and Natural Science; Princeton University Press: Princeton, NJ, USA, 2009.

152. Weyl, H. Mind and Nature: Selected Writings on Philosophy, Mathematics, and Physics; Princeton University Press: Princeton, NJ, USA, 2009.

153. Epperson, M. Foundations of Relational Realism: A Topological Approach to Quantum Mechanics and the Philosophy of Nature; Lexington Books: Lanham, MD, USA, 2013.

154. Malpas, J. Heidegger's Topology: Being, Place, World; MIT: Cambridge, MA, USA; London, UK, 2008.

155. Russell, B. The Principles of Mathematics; W.W. Norton: New York, NY, USA, 1996.

156. Russell, B. Collected Writings, Volume III: Toward the Principles of Mathematics: 1900-02; Routledge: London, UK; New York, NY, USA, 1993.

157. Whitehead, A.; Russell, B. Principia Mathematica: Volume I; Rough Draft Printing: San Bernardio, CA, USA, 2011.

158. Whitehead, A.; Russell, B. Principia Mathematica: Volume II; Rough Draft Printing: San Bernardio, CA, USA, 2011.

159. Whitehead, A.; Russell, B. Principia Mathematica: Volume III; Rough Draft Printing: San Bernardio, CA, USA, 2011.

160. Plato. Timaeus and Critias; Oxford University Press: Oxford, UK; New York, NY, USA, 2008.

161. Barbour, J. The Discovery of Dynamics: A Study from a Machian Point of View of the Discovery and the Structure of Dynamical Theories; Oxford University Press: Oxford, UK; New York, NY, USA, 2001.

162. Russell, B. My philosophical Development; Spokesman: Nottingham, UK, 2007.

163. Badiou, A. Being and Event; Bloomsbury Academic: New York, NY, USA, 2013.

164. Bohm, D. Quantum Theory; Dover Publications: New York, NY, USA, 1989.

165. Bohm, D. The Undivided Universe: An Ontological Interpretation of Quantum Theory; Routledge: London, UK; New York, NY, USA, 1993.

166. Epperson, M. Quantum Mechanics and the Philosophy of Alfred North Whitehead; Fordham University Press: New York, NY, USA, 2012.

167. Reichenbach, H. From Copernicus to Einstein; Read Books Ltd.: Redditch, UK, 2013.

168. Heisenberg, W. Physics and Philosophy: The Revolution in Modern Science; HarperPerennial: New York, NY, USA, 2007.

169. Wheeler, J. Geons, Black Holes, and Quantum Foam: A Life in Physics; Norton: New York, NY, USA, 2000.

170. Rovelli, C. Reality Is Not What it Seems: The Journey to Quantum Gravity; Riverhead Books: New York, NY, USA, 2018.

171. Shimony, A. Search for a Naturalistic World View, Volume I; Cambridge University Press: Cambridge, UK; New York, NY, USA, 1993.

172. Shimony, A. Search for a Naturalistic World View, Volume II; Cambridge University Press: Cambridge, UK; New York, NY, USA, 1993. 
173. Omnes, R. Quantum Philosophy: Understanding and Interpreting Contemporary Science; Princeton University Press: Princeton, NJ, USA, 1999.

174. Schelling, F. The Philosophy of Art; University of Minnesota Press: Minneapolis, MN, USA, 1989.

175. Schelling, F. The Ages of the World; State University of New York Press: Albany, NY, USA, 2000.

176. Penrose, R. The Road to Reality: A Complete Guide to the Laws of the Universe; Vintage Books: New York, NY, USA, 2007.

177. Monod, J. Chance and Necessity: An Essay on the National Philosophy of Modern Biology; Fontana: London, UK, 1974.

178. Jacob, F. The Logic of Life: A History of Heredity; Princeton University Press: Princeton, NJ, USA, 1993.

179. Darwin, C. The Origin of Species by Means of Natural Selection; Barnes \& Noble Classics: New York, NY, USA, 2004.

180. Gould, S. The Structure of Evolutionary Theory; Belknap Press of Harvard University Press: Cambridge, MA, USA, 2002.

181. Gould, S. Wonderful Life: The Burgess Shale and the Nature of History; W.W. Norton \& Company: New York, NY, USA, 1989.

182. Dawkins, R. The Selfish Gene; Oxford University Press: Oxford, UK, 2016.

183. Hoffmeyer, J. Biosemiotics: An Examination into the Signs of Life and the Life of Signs; University of Scranton Press: Scranton, PA, USA, 2008.

184. Zhegunov, G. The Dual Nature of Life: Interplay of the Individual and the Genome; Springer: Berlin, Germany; New York, NY, USA, 2012.

185. Ward, P. Lamarck's Revenge: How Epigenetics Is Revolutionizing Our Understanding of Evolution's Past and Present; Bloomsbury Publishing, Inc.: New York, NY, USA, 2018.

186. Baedke, J. Above the Gene, Beyond Biology: Toward a Philosophy of Epigenetics; University of Pittsburgh Press: Pittsburgh, PA, USA, 2018.

187. Peterson, E. The Life Organic: The Theoretical Biology Club and the Roots of Epigenetics; University of Pittsburgh Press: Pittsburgh, PA, USA, 2016.

188. Petkov, V. Relativity and the Nature of Spacetime; Springer: Dordrecht, The Netherlands; New York, NY, USA, 2009.

189. Mikki, S. On the Direction of Time: From Reichenbach to Prigogine and Penrose. Philosophies 2021, 6, 79. [CrossRef]

190. Schopenhauer, A. The World as Will and Representation, Volume 1; Cambridge University Press: Cambridge, UK, 2014.

191. Schopenhauer, A. The World as Will and Representation, Volume 2; Cambridge University Press: Cambridge, UK, 2020.

192. Jung, C.G. The Archetypes and the Collective Unconscious; Routledge: London, UK, 1990.

193. Hartmann, E. Philosophy of the Unconscious: Speculative Results According to the Inductive Method of Physical; Routledge: London, UK, 2010.

194. Lucretius. The Nature of Things; Norton: New York, NY, USA, 1977.

195. Guattari, F. The Anti-Oedipus Papers; Semiotext(e) Distributed by MIT Press: New York, NY, USA; Cambridge, MA, USA, 2006.

196. Uexkull, J. A Foray Into the Worlds of Animals and Humans: With A Theory of Meaning; University of Minnesota Press: Minneapolis, MN, USA, 2010.

197. Deleuze, G. Cinema 1: The Movement-Image; University of Minnesota: Minneapolis, MN, USA, 1986.

198. Deleuze, G. Cinema 2: The Time-Image; University of Minnesota: Minneapolis, MN, USA, 1986.

199. Deleuze, G. Pure Immanence: Essays on a Life; Zone Books Distributed by the MIT Press: New York, NY, USA; Cambridge, MA, USA, 2001.

200. Lorenz, K. The Natural Science of the Human Species: An Introduction to Comparative Behavioral Research, the Russian Manuscript (1944-1948); MIT Press: Cambridge, MA, USA, 1996.

201. Kauffman, S. The Origins of Order: Self-Organization and Selection in Evolution; Oxford University Press: New York, NY, USA, 1993.

202. Smolin, L. The Life of the Cosmos; Oxford University Press: New York, NY, USA, 1997.

203. Heidegger, M. The Question Concerning Technology, and Other Essays; HarperCollins Publishers: New York, NY, USA, 2013.

204. Maxwell, J. Maxwell on Molecules and Gases; MIT Press: Cambridge, MA, USA, 1986.

205. Boltzmann, L. Theoretical Physics and Philosophical Problems: Selected Writings; Reidel Pub. Co: Dordrecht, The Netherlands; Boston, MA, USA, 1974.

206. Cassirer, E. Determinism and Indeterminism in Modern Physics: Historical and Systematic Studies of the Problem of Causality; Yale University Press: New Haven, CT, USA, 1956.

207. Lacan, J. Ecrits: The First Complete Edition in English; Norton: New York, NY, USA, 2006.

208. Heidegger, M. The Principle of Reason; Indiana University Press: Bloomington, IN, USA, 1996.

209. Reichenbach, H. The Philosophy of Space \& Time; Dover Publications: New York, NY, USA, 1958.

210. Reichenbach, H. The Direction of Time; Dover: Mineola, NY, USA, 1999.

211. Reichenbach, H. Selected Writings: Volume I; D. Reidel Pub. Co: Dordrecht, The Netherland, 1978.

212. Reichenbach, H. Selected Writings: Volume II; D. Reidel Pub. Co: Dordrecht, The Netherland, 1978.

213. Mikki, S. On Russell's 1927 Book The Analysis of Matter. Philosophies 2021, 6, 40. [CrossRef]

214. Newton, I. Isaac Newton: Philosophical Writings; Cambridge University Press: New York, NY, USA, 2014.

215. Fanning, P. Isaac Newton and the Transmutation of Alchemy: An Alternate View of the Scientific Revolution; North Atlantic Books: Berkeley, CA, USA, 2009.

216. Einstein, A.; Infeld, L. The Evolution of Physics: From Early Concepts to Relativity and Quanta; Simon and Schuster: New York, NY, USA, 1966.

217. Eddington, A. The Nature of the Physical World (The Gifford Lectures: 1927); Books on Demand: Norderstedt, Germany, 2019. 
218. Kant, I. Critique of Pure Reason; Dover Publications: Mineola, NY, USA, 2003.

219. Kant, I. Metaphysical Foundations of Natural Science; Cambridge University Press: Cambridge, UK; New York, NY, USA, 2004.

220. Husserl, E. Ideas Pertaining to a Pure Phenomenology and to a Phenomenological Philosophy; M. Nijhoff Distributors: Boston, MA, USA, 1980.

221. Graham, D. The Texts of Early Greek Philosophy: The Complete Fragments and Selected Testimonies of the Major Presocratics; Cambridge University Press: New York, NY, USA, 2010.

222. Laertius, D. Lives of the Eminent Philosophers; Oxford University Press: New York, NY, USA, 2020.

223. Karatani, K. Isonomia and the Origins of Philosophy; Duke University Press: Durham, UK, 2017.

224. Schelling, F. Philosophy of Revelation (1841-42): And Related Texts; Spring Publications: Thompson, CT, USA, 2020.

225. Whitehead, A. Modes of Thought; Free Press: New York, NY, USA, 1968.

226. Jung, C.G. Psychology and Religion: The Collected Works of C.G. Jung, Volume 11; Princeton University Press: Princeton, NJ, USA, 1975.

227. Mitchell, A. The Fourfold: Reading the Late Heidegger; Northwestern University Press: Evanston, IL, USA, 2015.

228. Lautman, A. Mathematics, Ideas, and the Physical Real; Continuum: New York, NY, USA, 2010.

229. Hausdorff, F. Set Theory; American Mathematical Society: Providence, RI, USA, 2005.

230. Pontryagin, L.S. Topological Groups; Gordon and Breach Science Publishers: New York, NY, USA, 1986.

231. DeLanda, M. Intensive Science and Virtual Philosophy; Bloomsbury: New York, NY, USA, 2013.

232. Lie, S. Theory of Transformation Groups I; Springer: Berlin/Heidelberg, Germany, 2015.

233. Godement, R. Introduction to the Theory of Lie Groups; Springer: Cham, Switzerland, 2017.

234. Montgomery, D.; Zippin, L. Topological Transformation Groups; Dover Publications, Inc.: Mineola, NY, USA, 2018.

235. Ellis, R. Lectures on Topological Dynamics; W.A. Benjamin: New York, NY, USA, 1969.

236. Gottschalk, W.; Hedlund, G.A. Topological Dynamics; American Mathematical Society: Providence, RI, USA, 1955.

237. Akin, E. Recurrence in Topological Dynamics: Furstenberg Families and Ellis Actions; Plenum Press: New York, NY, USA, 1997.

238. Rovelli, C. Quantum Gravity; Cambridge University Press: Cambridge, UK; New York, NY, USA, 2004.

239. Rovelli, C. Covariant loop Quantum Gravity: An Elementary Introduction to Quantum Gravity and Spinfoam Theory; Cambridge University Press: Cambridge, UK; New York, NY, USA, 2015.

240. Fichte, J. Foundations of Transcendental Philosophy (Wissenschaftslehre) nova Methodo (1796/99); Cornell University Press: Ithaca, NY, USA, 1992.

241. Whitehead, A. Science and Philosophy; Philosophical Library: New York, NY, USA, 1974.

242. Murray, J. Deleuze \& Guattari: Emergent Law; Routledge: Oxfordshire, UK, 2013.

243. Russell, B. The Philosophy of Logical Atomism; Open Court: LaSalle, IL, USA, 1985.

244. Russell, B. Introduction to Mathematical Philosophy; Barnes \& Noble: New York, NY, USA, 2005.

245. Deleuze, G. Empiricism and Subjectivity: An Essay on Hume's Theory of Human Nature; Columbia University Press: New York, NY, USA, 1991.

246. Sell, G. Topological Dynamics and Ordinary Differential Equations; Van Nostrand-Reinhold: London, UK; New York, NY, USA, 1971.

247. Whitehead, A. The Principle of Relativity; Cosimo Classics: New York, NY, USA, 2007. 